\title{
In-depth phenotyping for clinical stratification of Gaucher disease
}

\author{
Simona D'Amore ${ }^{1 \dagger}$, Kathleen Page ${ }^{1 \dagger}$, Aimée Donald ${ }^{1,4,11 \dagger}$, Khadijeh Taiyari2, ${ }^{2,2}$, Brian Tom ${ }^{2}$, Patrick Deegan ${ }^{3}$, \\ Chong Y. Tan ${ }^{3}$, Kenneth Poole ${ }^{1}$, Simon A. Jones ${ }^{4}$, Atul Mehta ${ }^{5}$, Derralynn Hughes ${ }^{5}$, Reena Sharma ${ }^{6}$, \\ Robin H. Lachmann ${ }^{7}$, Anupam Chakrapani ${ }^{8}$, Tarekegn Geberhiwot ${ }^{9}$, Saikat Santra ${ }^{10}$, Siddarth Banka ${ }^{4}$, \\ Timothy M. Cox ${ }^{1,3^{*}}$ id and the MRC GAUCHERITE Consortium
}

\begin{abstract}
Background: The Gaucher Investigative Therapy Evaluation is a national clinical cohort of 250 patients aged 5-87 years with Gaucher disease in the United Kingdom — an ultra-rare genetic disorder. To inform clinical decisionmaking and improve pathophysiological understanding, we characterized the course of Gaucher disease and explored the influence of costly innovative medication and other interventions. Retrospective and prospective clinical, laboratory and radiological information including molecular analysis of the GBA1 gene and comprising $>2500$ variables were collected systematically into a relational database with banking of collated biological samples in a central bioresource. Data for deep phenotyping and life-quality evaluation, including skeletal, visceral, haematological and neurological manifestations were recorded for a median of 17.3 years; the skeletal and neurological manifestations are the main focus of this study.
\end{abstract}

Results: At baseline, 223 of the 250 patients were classified as type 1 Gaucher disease. Skeletal manifestations occurred in most patients in the cohort (131 of 201 specifically reported bone pain). Symptomatic osteonecrosis and fragility fractures occurred respectively in 76 and 37 of all 250 patients and the first osseous events occurred significantly earlier in those with neuronopathic disease. Intensive phenotyping in a subgroup of 40 patients originally considered to have only systemic features, revealed neurological involvement in 18: two had Parkinson disease and 16 had clinical signs compatible with neuronopathic Gaucher disease-indicating a greater than expected prevalence of neurological features. Analysis of longitudinal real-world data enabled Gaucher disease to be stratified with respect to advanced therapies and splenectomy. Splenectomy was associated with an increased hazard of fragility fractures, in addition to osteonecrosis and orthopaedic surgery; there were marked gender differences in fracture risk over time since splenectomy. Skeletal disease was a heavy burden of illness, especially where access to specific therapy was delayed and in patients requiring orthopaedic surgery.

Conclusion: Gaucher disease has been explored using real-world data obtained in an era of therapeutic transformation. Introduction of advanced therapies and repeated longitudinal measures enabled this heterogeneous condition to be stratified into obvious clinical endotypes. The study reveals diverse and changing phenotypic manifestations with systemic, skeletal and neurological disease as inter-related sources of disability.

\footnotetext{
*Correspondence: tmc12@medschl.cam.ac.uk

†'Simona D'Amore, Kathleen Page and Aimée Donald have contributed

equally to the manuscript

1 Department of Medicine, University of Cambridge, Cambridge, UK

Full list of author information is available at the end of the article
} permits use, sharing, adaptation, distribution and reproduction in any medium or format, as long as you give appropriate credit to the original author(s) and the source, provide a link to the Creative Commons licence, and indicate if changes were made. The images or other third party material in this article are included in the article's Creative Commons licence, unless indicated otherwise in a credit line to the material. If material is not included in the article's Creative Commons licence and your intended use is not permitted by statutory regulation or exceeds the permitted use, you will need to obtain permission directly from the copyright holder. To view a copy of this licence, visit http://creativecommons.org/licenses/by/4.0/. The Creative Commons Public Domain Dedication waiver (http://creativeco mmons.org/publicdomain/zero/1.0/) applies to the data made available in this article, unless otherwise stated in a credit line to the data. 
Keywords: Gaucher disease, Cohort, GAUCHERITE, Enzyme replacement therapy, Substrate reduction therapy, Disease-modifying therapies

\section{Background}

Gaucher disease is an autosomal recessive disorder of sphingolipid metabolism caused by catalytic deficiency of lysosomal acid $\beta$-D-glucosylceramidase ( $\beta$-glucocerebrosidase; EC 3.2.1.45) [1, 2]. Impaired lysosomal recycling of $\beta$-glucosylceramides leads to over-production of $B$-glucosylsphingosine. This ultra-rare inborn error is principally caused by biallelic mutations in the GBA1 gene located on chromosome 1q22 [2] and is most frequent in Ashkenazi Jews and occurs in small isolated populations in North Sweden and Brazil [3-5].

A convenient, but imperfect clinical classification of Gaucher disease, recognises three principal subtypes: type 1 (GD1, OMIM 230800, chronic nonneuronopathic), type 2 (GD2, OMIM 230900, acute neuronopathic) and type 3 (GD3, OMIM 231000, chronic neuronopathic) diseases [2]. This operational classification is summarized in Additional file 1: Table S1. However, a striking feature in all subtypes, is the heterogeneity of this disease in the age and rate of onset, as well as the widespread effects. Especially in the type 1 disease, adults as well as children can have only mild symptoms or be asymptomatic. Marked differences of disease expression are seen between affected siblings and clinically discordant monozygotic twins suggest not only the existence of modifier genes but complex interactions with environmental factors [2, 6-9].

Evidence of disease is detectable in the bone marrow and macrophage-rich organs such as the spleen and liver where dynamic recycling of membrane sphingolipids derived from blood cells occurs. Glycosphingolipid accumulation in engorged, often multinuclear histiocytes, generates the pathognomonic Gaucher cell [6]. With the exception of the nervous system, functional disturbances and tissue injury occur at sites where macrophages are most abundant, such as the skeleton (marrow), spleen, liver and sometimes the lung $[2,6,8,10]$. Systemic manifestations reflect combinations of bone marrow and visceral involvement due to activation of histiocytes with local inflammatory responses; fibrosis with scarring may follow. In patients with symptomatic disease, a sustained inflammatory state is accompanied by release of cytokines and hepatosplenomegaly and in children, delayed growth and puberty [11-13]. In the absence of specific therapy, massive splenomegaly complicated by cytopenias may necessitate splenectomy. Gaucher disease may impair skeletal development with defective modelling, poor mineralization, osteolytic lesions and osteonecrosis-the latter mainly occurring at the epiphyses of long bones. Osteonecrosis may be explained by compromised blood flow in the growth plate microvasculature (Fig. 1 and Additional file 2: Fig. S1). It may be driven by glucosylceramide-related activation of macrophage-inducible C-type lectin (Mincle) with effects on osteocytes $[14,15]$.

The neurological complications are also not fully understood but unlike the pathology in macrophagerich tissues, mainly reflect impaired lysosomal recycling of endogenous glucosylceramide derived from the membrane turnover in long-lived neural cells although perivascular accumulation of pathological storage macrophages in cerebral and cerebellar sub-cortical white matter occurs in chronic neuronopathic disease (as in Norrbottnian patients). However, neuronophagia with microglial satellitosis in the cerebral cortex and dentate nucleus occurs with biochemical and ultrastructural evidence of glucosylceramide and psychosine excess, the latter apparently correlated with neuronal loss $[16,17]$. Systematic neuropathological studies after necropsy in thirteen patients classified across all three subtypes, including those with parkinsonism and dementia (with Lewy bodies containing synuclein) in type 1, identified distribution of disease uniquely affecting cerebral cortical layers 3 and 5, hippocampal CA2-4, and layer 4b of the calcarine cortex correlated with neurological impairment [18]. Prominent neuronal loss occurred in acute neuronopathic (type 2) and chronic neuronopathic disease (type 3) with progressive myoclonic encephalopathy; astrogliosis was the only neuropathological finding in 'non-neuronopathic' Gaucher disease.

In resource-rich countries, patients with Gaucher disease have access to transformative molecular therapies which address its systemic and skeletal manifestations. However, in many countries availability of these advanced medications is restricted by cost and by the practical arrangements associated with high-cost recombinant proteins that must be given regularly by slow infusion. Current treatments include recombinant human glucosylceramidase modified for preferential targeting to macrophages and given intravenously, or oral therapies involving small molecules with distinct modes of action [8, 19-22]. The full licensed doses for initiating enzyme therapy (60 iu/Kg every two weeks) are not universally used because of the heterogeneity and the multi-systemic nature of Gaucher disease. This is generally accepted by regulatory authorities in the context of 'individualized' 


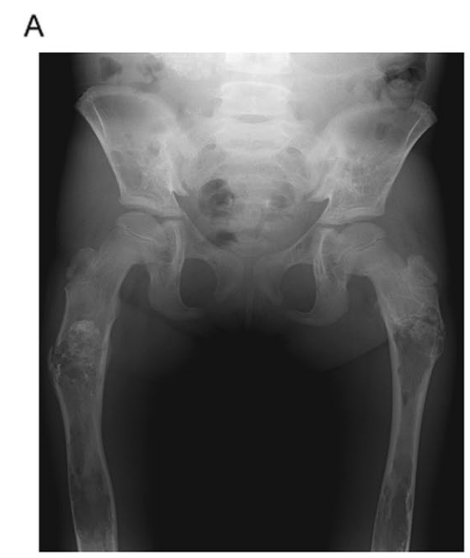

E

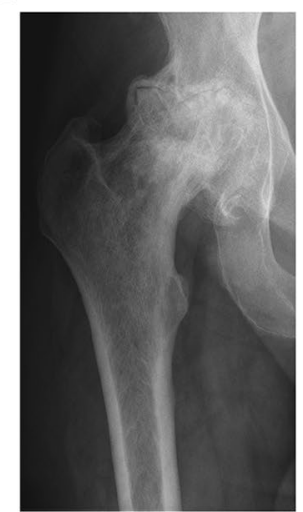

B

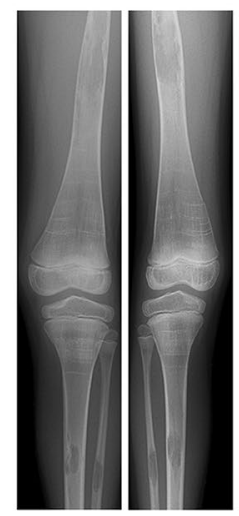

C

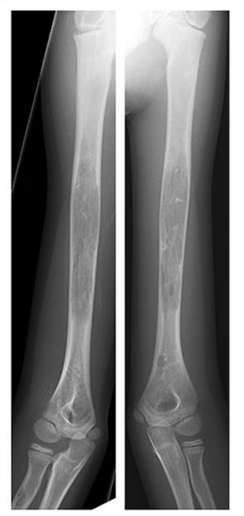

D

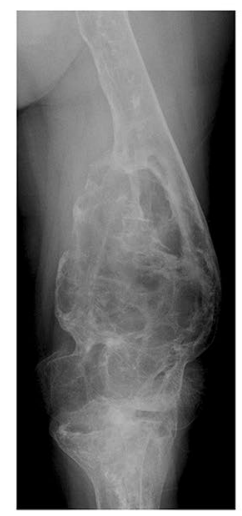

G

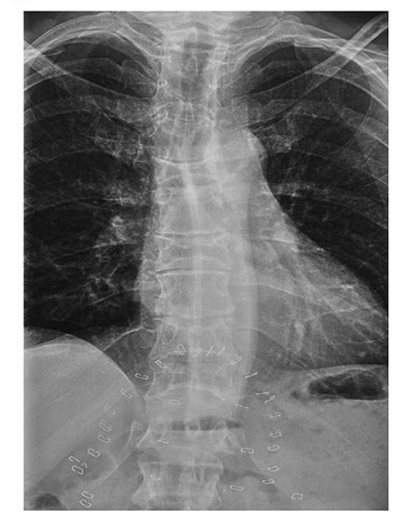

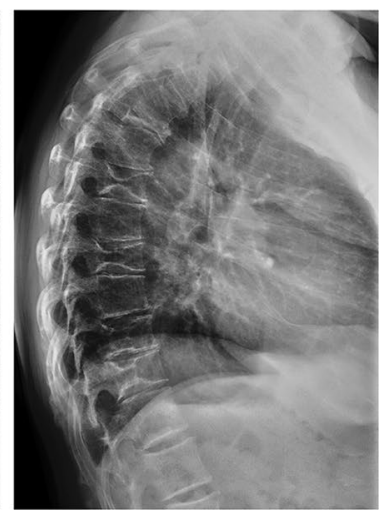

Fig. 1 Radiographic imaging of skeletal manifestations in Gaucher disease. Generalized osteopaenia and lytic areas in iliac wings (A) and mid shafts of both femora (A, B), tibiae (B) and humeri (C). Pathological fractures both upper femora (A). Erlenmeyer flask deformity of both femurs, also known as metaphyseal flaring (B). Gross expansion and coarse trabeculation of the left femur (D). Extensive osteonecrosis of the right femoral head, which shows marked flattening with complete loss of joint space (E). Prominent thoracic kyphosis and exaggerated lumbar lordosis with minimal lumbar curve (F). H-shaped vertebrae of the thoracic spine consistent with osteonecrosis (G)

therapy. Once the individual patient response for all relevant clinical manifestations is established, dosages and frequency of administration may be adjusted with the goal to either maintain already reached optimal parameters for all clinical manifestations or further improve those clinical parameters which have not yet been normalised. While there is a trend to lower doses in resource-poor settings, some insurers/ payers in relatively rich countries challenge costs; where monitoring is not optimal or expertise lacking, dosing may not control disease in all compartments.

Hitherto, two systemically active oral preparations, miglustat and eliglustat, based on the principle of substrate restriction have been approved for type 1 Gaucher disease. These molecules can attenuate the biosynthesis of glucosylceramide to allow the residual lysosomal digestive function to clear the pathological excess of the sphingolipid [23-29]. Targeted enzyme therapy is available for type 1 and the systemic manifestations of type 3
Gaucher disease. In the United Kingdom (UK), decisions about treatment are determined by expert physicians guided by patient preference and local prescribing rules.

The variable course of Gaucher disease and availability of specific therapies with distinct modes of action prompted us to seek a better understanding of its response to different interventions. To quantify the effects of treatment, we explored data collected during long-term real-world delivery of care over several decades of specialist practice across the UK and built a platform based on repeated measures and in-depth clinical phenotyping. With an engaged national cohort of patients attending specialist centres, we collected retrospective and prospective data in those with a confirmed clinical, biochemical and genetic diagnosis. Funded principally by the UK Medical Research Council, the Gaucher Investigative Therapy Evaluation (GAUCHERITE), enrolled 250 patients aged 5-87 years. The cohort includes patients with all but the most acute neurological 
forms of the disease (type 2, OMIM 230900 and the sporadic lethal perinatal form, OMIM 608013).

Once established, the skeletal and neurological features of Gaucher disease become irreversible causes of disability: hence these domains were chosen for detailed study. Here we report the clinical and radiological characteristics of the cohort in which the known determinants of outcome are recorded: these include clinical severity scores and the onset and rate of disease progression in the context of different interventions (e.g. splenectomy or molecular therapy). With extensive imaging, exploration of potential biomarkers and longitudinally repeated in-depth determinations, we have established a data-rich analytical platform further to investigate pathogenesis. To inform optimal management, the ultimate aim of this work is to define therapeutic endotypes of Gaucher disease. Combined with extensive haematological and biochemical testing, as well as imaging and DXA studies, these activities meet the criteria for deep phenotyping [30].

\section{Materials and methods Study design}

In the UK, treatment for Gaucher disease is available only at specialist centres approved by the National Health Service (NHS). All patients attending each of the eight NHS specialist centres in England (Additional file 1: Table S2) were invited to participate. Clinical, radiological and laboratory data, including case report forms and other study documents, were securely recorded in the bespoke, webbased, relational GAUCHERITE database using unique identifier numbers for each centre and the individual patients attending.

Data were collected at defined intervals and transcribed from GAUCHERITE clinical study forms that include records of structured physical examinations preceded by completion of a dedicated health questionnaire. The clinical interrogation was mainly directed to skeletal events, physical manifestations and specialised neurology; comorbidities were also captured. Separately, patients or carers completed detailed quality-of-life, fatigue, health and anxiety questionnaires; specific questions were related to growth measures, as well as voice changes or breast development, as well as the age at menarche and the menopause. All treatments were recorded with emphasis on therapies directed to bone disease as well as the dosing of, and adherence to, molecular therapies administered specifically for Gaucher disease.

As set out in Additional file 1: Table S3, plasma and serum biomarkers have been measured over intervals and the data captured-including the tissue-response analytes, chitotriosidase activity and the concentration of $\mathrm{CC}$ chemokine pulmonary and activation-regulated chemokine (PARC)/CCL18. From the outset, a tissue biobank was developed (curated by FMP, Gaucherite CoPrincipal Investigator). Biological material was collected from 238 patients (182 with serial samples) and frozen. This resource is suitable for analysis of sphingolipid biomarkers, including unacylated metabolites of glucosylceramide; genomic DNA is also retained for future analysis in ethically approved research studies.

\section{Study population}

Two hundred and fifty patients with a confirmed diagnosis of Gaucher disease were enrolled between May 2015 to October 2017; this pre-set target, included adults and children and represents $\approx 85 \%$ of all those patients known in the UK $(<290)$. The database was locked in July 2018 , allowing $0.5-3$ years of prospective data to be collected and retrospective data from $>2-25$ years. The patients included those diagnosed with the so-called non-neuronopathic (type 1) and chronic neuronopathic (type 3) disease variants. Patients likely to die within six months, those unable to understand the consent form, or those otherwise judged unsuitable by the investigator, were not recruited. These constitute a group of more than 50 known to have died since 1990 with longitudinal data also held on the database and shortly to be reported.

Definitive diagnosis of Gaucher disease was based on enzymatic assay in leukocytes or skin fibroblasts; this was supported by molecular analysis of the GBA1 gene, except in one adult patient with a genetically confirmed diagnosis of saposin $\mathrm{C}$ deficiency (later treated with eliglustat). Genotyping was carried out in regional NHS diagnostic services by targeted Sanger sequencing using GBA1 primers (Transcript: NM_000157.3) for 11 individual exons and intron boundaries using Primer3Plus to obtain PCR amplification products from all coding sequences and those in flanking intronic regions. Conventional nomenclature was used to describe $G B A 1$ mutations and principally employs a long-established protein designation derived from AAC63056.1 [31]; in this manuscript, when first describing mutant GBA1 alleles, the 2016 HGVS nomenclature [32] is also used.

\section{Data collection}

Prospective and retrospective clinical data were entered into the GAUCHERITE electronic case report form, including, for adult patients, medical records held at former paediatric specialist centres. The median number of visits was $26.1(28.1 \pm 17.4$, mean \pm standard deviation, $\mathrm{SD})$ and median follow-up was 17.3 years, range up to 55 years $(16.5 \pm 9.2$, mean \pm SD). One child, aged 5 years, had clinical data and investigations entered on enrolment but was not further followed up during the study period. All these data including archived medical imaging studies 
(Additional file 1: Table S3) were anonymised. Regular data audits were conducted to ensure quality and completeness. A detailed description of the parameters collected is set out in the Additional file 1. Saccadic eye movements were measured prospectively under separate ethical approval in a consented subset of subjects using the EyeSeeCam device with a head-mounted camera for video-oculography [33, 34].

Fragility fracture was defined according to the World Health Organization [35] definition of low-impact fractures (see Additional file 1). The term "Symptomatic Osteonecrosis", as used here, represents an event recorded in the clinical record by the treating physician as osteonecrosis or avascular necrosis and supported by a description of characteristic symptoms; radiological confirmation was not required for this purpose.

\section{Statistical analysis}

Unless otherwise stated, baseline parameters are described at the time of enrolment into GAUCHERITE for all patients by reporting frequencies and proportions for categorical variables and summary statistics for continuous variables.

Time-to-event outcomes and repeated events data were described using Cox cumulative hazard functions and Andersen-Gill methods, respectively. Time origin for these analyses depended on the outcome and the specific research questions. Subjects were not included if relevant dates were not recorded. For the purpose of these analyses, database lock was July 312018 . To study the effect of age at initiation of enzyme therapy or substrate reduction therapy on time from presentation with Gaucher disease to bone manifestation, we initially examined six age categories (under 10,10-19, 20-29, 30-39, 40-49, and 50 years or older). Hazard ratios among the two younger groups and among the four older age groups was similar. Thus, for analytical purposes, age at initiation of specific treatment was stratified into two categories: younger than 20 years, and greater or equal to 20 years. Statistical significance was assessed at the $5 \%$ significance level after accounting for the possibility of model misspecification using robust standard errors; where used, 95\% confidence limits are shown in parentheses. The STATA SE v14.2 and $\mathrm{R}$ software programme was used for all analyses.

\section{Results}

\section{Population demographics and disease characteristics}

Table 1 shows the baseline characteristics of the cohort: the population is stratified by age (children, up to the age of 18 years; adults, 18 years or older) and the initially assigned subtype of Gaucher disease (type 1 and 3). Of the 250 patients (128 male and 122 female, median age 46 years, range: 5-87), 223 had a clinical diagnosis of non-neuronopathic type 1 Gaucher disease (120 males and 103 females; median age 48 years, range: 5-87) and 27 of neuronopathic type 3 Gaucher disease ( 8 male and 19 female; median age 23 years, range 5-60), as determined by the participating physician. Of note, 26 patients (13 male and 13 female; 17 type 1 and 9 type 3) were under 18 years of age when enrolled. Of the patients with type 1 Gaucher disease, 7 had Parkinson disease (median age of this diagnosis 52 years, range: $35-70$ ). Eighty-five patients had a family history of Parkinson disease and/or dementia.

Forty-three patients (17\%) stated that they were of Jewish descent; no patient of Jewish ancestry had neuronopathic (type 3) Gaucher disease. No other ethnic information was formalized for classification. Despite the rarity of the condition, overt consanguinity was identified in only 18 (7\%) of the parents. Onset of symptoms or signs attributed to Gaucher disease had occurred earlier in patients with type 3 disease (median at 1 year, range: $<1-16)$ compared with those assigned to the type 1 category (median age 13 years, range: $<1-72$ ). The most frequent presenting manifestation was an enlarged abdomen (15\%), often with a bleeding tendency (17\%). Other manifestations are set out in Table 1.

Most patients were diagnosed in childhood: the median age was 16 (range: $<1-73$ ) years. Those with type 3 disease were much younger at diagnosis (median age 2 years, range: $<1-16$ ) than type 1 (median age 20 years, range: $<1-73$ ). The ratio of females to males in this group is 2.4 but does not differ significantly from a random sample $\left(x^{2} 1.53\right.$ with Yates correction, $\left.p=0.216\right)$. Of note, 13 (5\%) patients did not give a history of Gaucherrelated symptoms: 8 were diagnosed as a result of family screening after an index case was identified; 4 were identified incidentally (test performed for a reason unrelated directly to health) and in one patient in response to other manifestations not considered to be Gaucherrelated. None was identified by prenatal diagnosis or newborn screening. Although the clinical diagnosis in all cases was suspected by a combination of features and acid $\beta$-glucosidase assay is now more often requested, historically the most common primary diagnostic indicator was bone marrow biopsy (29\%). Confirmation of the suspected diagnosis in all cases required either definitive measurement of enzyme activity (typically in peripheral blood leukocytes) or molecular analysis of GBA1 in genomic DNA. To detect recombinant alleles and those harbouring deletions such as the del55 bp, as well as novel $G B A 1$ variants, sequencing of the $G B A 1$ locus in genomic DNA was undertaken in the entire cohort (see methods and below). The procedure followed standard clinical sequencing practice to ensure that the functional 
Table 1 Clinical characteristics of the GAUCHERITE cohort and subgroups at recruitment

\begin{tabular}{|c|c|c|c|c|c|c|}
\hline Variables & Categories* & $\begin{array}{l}\text { Entire cohort } \\
(\mathrm{N}=250)[\%]\end{array}$ & $\begin{array}{l}\text { Children } \\
(\mathrm{N}=26)[\%]\end{array}$ & $\begin{array}{l}\text { Adults } \\
(\mathrm{N}=224)[\%]\end{array}$ & $\begin{array}{l}\text { Gaucher Type } \\
1(\mathrm{~N}=223) \\
{[\%]}\end{array}$ & $\begin{array}{l}\text { Gaucher Type } \\
3(\mathrm{~N}=27)[\%]\end{array}$ \\
\hline \multirow[t]{2}{*}{ Gender } & Male & $128[51]$ & $13[50]$ & $115[51]$ & $120[54]$ & $8[30]$ \\
\hline & Female & $122[49]$ & $13[50]$ & $109[49]$ & $103[46]$ & $19[70]$ \\
\hline \multirow[t]{2}{*}{ Recruitment age (y) } & Mean age $\pm S D$ & $44 \pm 19$ & $11 \pm 4$ & $48 \pm 16$ & $46 \pm 18$ & $26 \pm 16$ \\
\hline & Median (range) & $46(5-87)$ & $11(5-17.8)$ & $49(18.7-87)$ & $48(5-87)$ & $23(5-60)$ \\
\hline \multirow[t]{2}{*}{ Jewish descent } & Yes & $43[17]$ & $1[4]$ & $42[19]$ & $43[19]$ & - \\
\hline & No & 207 [83] & 25 [96] & $182[81]$ & $180[81]$ & 27 [100] \\
\hline \multirow[t]{2}{*}{ Consanguinity } & Yes & $18[7]$ & $2[8]$ & $16[7]$ & $9[4]$ & $9[33]$ \\
\hline & No & 232 [93] & $24[92]$ & 208 [93] & 214 [96] & 18 [67] \\
\hline \multirow[t]{4}{*}{ Age at symptom onset (y) } & Mean age $\pm S D$ & $16 \pm 15$ & $3 \pm 2$ & $18 \pm 15$ & $18 \pm 15$ & $3 \pm 4$ \\
\hline & Median (range) & $11(0-72)$ & $2(0-8)$ & $13(0-72)$ & $13(0-72)$ & $1(0-16)$ \\
\hline & No symptoms & 13 & - & 13 & 12 & 1 \\
\hline & Unknown & 5 & - & 5 & 4 & 1 \\
\hline \multirow[t]{10}{*}{ First symptoms } & Enlarged abdomen & $37[15]$ & $6[23]$ & $31[14]$ & 28 [12.5] & $9[33]$ \\
\hline & $\begin{array}{l}\text { Enlarged abdomen plus other } \\
\text { symptoms }\end{array}$ & $67[27]$ & $8[31]$ & $59[26]$ & $56[25]$ & $11[40]$ \\
\hline & Easy bleeding/bruising & $34[14]$ & $1[4]$ & $33[15]$ & $34[15]$ & - \\
\hline & $\begin{array}{l}\text { Easy bleeding/bruising plus other } \\
\text { symptoms }\end{array}$ & $36[14]$ & $4[15]$ & $32[14]$ & $35[16]$ & $1[4]$ \\
\hline & Fatigue & $9[4]$ & - & $9[4]$ & $9[4]$ & - \\
\hline & Fatigue plus other symptoms & $6[2]$ & - & $6[3]$ & $6[3]$ & - \\
\hline & Bone disease & $15[6]$ & - & $15[7]$ & $15[7]$ & - \\
\hline & $\begin{array}{l}\text { Other non-classical GD symp- } \\
\text { toms }\end{array}$ & $32[13]$ & $7[27]$ & $25[11]$ & $28[12.5]$ & $4[15]$ \\
\hline & No symptoms & $13[5]$ & - & $13[6]$ & $12[5]$ & $1[4]$ \\
\hline & Unknown & $1[<1]$ & - & $1[<1]$ & - & $1[4]$ \\
\hline \multirow[t]{3}{*}{ Presentation age (y) } & Mean age $\pm S D$ & $18 \pm 16$ & $3 \pm 2$ & $20 \pm 16$ & $20 \pm 16$ & $3 \pm 4$ \\
\hline & Median (range) & $13(0-72)$ & $2(0-8)$ & $16(0-72)$ & $16(0-72)$ & $2(0-16)$ \\
\hline & Missing age & 2 & - & 2 & 1 & 1 \\
\hline \multirow[t]{2}{*}{ Age at diagnosis (y) } & Mean age $\pm S D$ & $21 \pm 17$ & $4 \pm 3$ & $23 \pm 17$ & $23 \pm 17$ & $3 \pm 4$ \\
\hline & Median (range) & $16(0-73)$ & $3(1-10)$ & $20(0-73)$ & $20(0-73)$ & $2(0-16)$ \\
\hline \multirow[t]{9}{*}{ Diagnostic pathway } & Enzyme assay & $21[8]$ & $7[27]$ & $14[6]$ & $17[8]$ & $4[15]$ \\
\hline & GBA-gene sequencing & $23[9]$ & $1[4]$ & $22[10]$ & $23[10]$ & - \\
\hline & Bone marrow histology & $71[29]$ & $3[11]$ & 68 [30] & 68 [30] & $3[11]$ \\
\hline & Liver histology & $12[5]$ & $2[8]$ & $10[5]$ & $11[5]$ & $1[4]$ \\
\hline & Spleen histology & $11[4]$ & - & $11[5]$ & $9[4]$ & $2[7]$ \\
\hline & Other histology & $1[<1]$ & - & $1[<1]$ & $1[<1]$ & - \\
\hline & Combination of these methods & $105[42]$ & $13[50]$ & $92[41]$ & $89[40]$ & $16[59]$ \\
\hline & Clinical history & $5[2]$ & - & $5[2]$ & $5[2]$ & - \\
\hline & Unknown & $1[<1]$ & - & $1[<1]$ & - & $1[4]$ \\
\hline \multirow[t]{4}{*}{ Parkinson disease } & Yes & $7[3]$ & - & $7[3]$ & $7[3]$ & - \\
\hline & $\begin{array}{l}\text { Age at diagnosis, years, } \\
\text { mean } \pm S D\end{array}$ & $54 \pm 12$ & - & $54 \pm 12$ & $54 \pm 12$ & - \\
\hline & Median (range) & $52(35-70)$ & - & $52(35-70)$ & $52(35-70)$ & - \\
\hline & No & $243[97]$ & $26[100]$ & $217[97]$ & 216 [97] & 27 [100] \\
\hline \multirow{2}{*}{$\begin{array}{l}\text { Family history of Parkinson/ } \\
\text { dementia }\end{array}$} & Yes & $85[34]$ & $4[15]$ & $81[36]$ & $76[34]$ & $9[33]$ \\
\hline & No & $165[66]$ & $22[85]$ & $143[64]$ & $147[66]$ & 18 [67] \\
\hline
\end{tabular}


Table 1 (continued)

\begin{tabular}{|c|c|c|c|c|c|c|}
\hline Variables & Categories* & $\begin{array}{l}\text { Entire cohort } \\
(\mathrm{N}=250)[\%]\end{array}$ & $\begin{array}{l}\text { Children } \\
(\mathrm{N}=26)[\%]\end{array}$ & $\begin{array}{l}\text { Adults } \\
(\mathrm{N}=224)[\%]\end{array}$ & $\begin{array}{l}\text { Gaucher Type } \\
1(\mathrm{~N}=223) \\
{[\%]}\end{array}$ & $\begin{array}{l}\text { Gaucher Type } \\
3(\mathrm{~N}=27)[\%]\end{array}$ \\
\hline \multirow[t]{11}{*}{ GBA1 Genotypes } & N370S/N370S & 33 & - & 33 & 33 & - \\
\hline & L444P/L444P & 20 & 6 & 14 & - & 20 \\
\hline & R463C/R463C & 2 & - & 2 & 2 & - \\
\hline & W184R/W184R & 1 & - & 1 & 1 & - \\
\hline & N370S/L444P & 38 & - & 38 & 38 & - \\
\hline & N370S/other & 106 & 11 & 95 & 106 & - \\
\hline & L444P/R463C & 12 & 2 & 10 & 11 & 1 \\
\hline & L444P/other & 7 & 2 & 5 & 4 & 3 \\
\hline & R463C/other & 15 & 2 & 13 & 13 & 2 \\
\hline & Other /other & 14 & 2 & 12 & 13 & 1 \\
\hline & $\begin{array}{l}\text { Unknown/NA* } \\
{ }^{*} \text { heterozygous PSAP mutations }\end{array}$ & 2 & 1 & 1 & 2 & - \\
\hline \multirow[t]{3}{*}{ Failure to thrive in childhood } & Yes & $65[26]$ & - & 65 [29] & $56[25]$ & $9[33]$ \\
\hline & No & $141[56]$ & - & $141[63]$ & $134[60]$ & $7[26]$ \\
\hline & Unknown/NA & $44[18]$ & 26 [100] & $18[8]$ & $33[15]$ & $11[41]$ \\
\hline \multirow{3}{*}{$\begin{array}{l}\text { Considered shorter than school } \\
\text { peers }\end{array}$} & Yes & $86[35]$ & - & $86[38]$ & $77[34.5]$ & $9[33]$ \\
\hline & No & $123[49]$ & - & $123[55]$ & 116 [52] & $7[26]$ \\
\hline & Unknown/NA & $41[16]$ & 26 [100] & $15[7]$ & 30 [13.5] & $11[41]$ \\
\hline \multirow{3}{*}{$\begin{array}{l}\text { Considered themselves under- } \\
\text { weight }\end{array}$} & Yes & $71[29]$ & - & $71[32]$ & 64 [29] & $7[26]$ \\
\hline & No & $138[55]$ & - & $138[61]$ & $129[58]$ & $9[33]$ \\
\hline & Unknown/NA & $41[16]$ & 26 [100] & $15[7]$ & $30[13]$ & $11[41]$ \\
\hline \multirow[t]{3}{*}{ Delayed puberty } & Yes & $54[22]$ & - & $54[24]$ & $49[22]$ & $5[18]$ \\
\hline & No & $148[59]$ & - & $148[66]$ & $137[61]$ & $11[41]$ \\
\hline & Unknown/NA & 48 19] & 26 [100] & 22 10] & $37[17]$ & $11[41]$ \\
\hline \multirow{8}{*}{$\begin{array}{l}\text { Onset of regular shaving/men- } \\
\text { ses, N }\end{array}$} & Male & 101 [79] & - & $101[88]$ & $96[80]$ & $5[63]$ \\
\hline & Years, mean age $\pm S D$ & $17 \pm 2$ & - & $17 \pm 2$ & $17 \pm 2$ & $20 \pm 4$ \\
\hline & Median (range) & $16(9-26)$ & - & $16(9-26)$ & $16(9-23)$ & $18(16-26)$ \\
\hline & Missing/NA & 27 & 13 & 14 & 24 & 3 \\
\hline & Female & $100[82]$ & - & 100 [92] & $89[86]$ & $11[58]$ \\
\hline & Years, mean age $\pm S D$ & $14 \pm 2$ & - & $14 \pm 2$ & $14 \pm 2$ & $13 \pm 2$ \\
\hline & Median (range) & $14(6-19)$ & - & $14(6-19)$ & $14(6-19)$ & $13(11-16)$ \\
\hline & Missing/NA & 22 & 13 & 9 & 14 & 8 \\
\hline \multirow[t]{3}{*}{ Menopause, N } & Yes & $51[42]$ & - & $51[47]$ & $48[47]$ & $3[16]$ \\
\hline & Age occurred years mean $\pm S D$ & $46 \pm 7$ & - & $46 \pm 7$ & $46 \pm 7$ & $39 \pm 10$ \\
\hline & Median age (range) & $47(26-58)$ & - & $47(26-58)$ & $47(26-58)$ & $36(31-51)$ \\
\hline \multirow[t]{3}{*}{ HRT status } & Yes & $20[39]$ & - & $20[39]$ & $18[38]$ & $2[67]$ \\
\hline & No & 29 57] & - & $29[57]$ & $28[58]$ & $1[33]$ \\
\hline & Missing & 2 & - & 2 & 2 & - \\
\hline
\end{tabular}

HRT hormone replacement therapy, NA not applicable, SD standard deviation

${ }^{*}$ Categorical variables are expressed as frequency [percent]. Continuous variables are expressed as mean \pm SD and median (range)

gene and not the vicinal $G B A$ pseudogene was amplified for characterization in isolation.

Complete genomic sequencing identified causal mutations of the GBA1 gene in 248 patients (Additional file 1: Table S7); one patient harboured two previously unknown mutant alleles and in one sibling of a known patient, no DNA was available for analysis; two mutant PSAP alleles in trans had been determined 
in one adult. The most common GBA1 variant was p.Asn409Ser (N370S) followed by p.Leu483Pro (L444P) and p.Arg502Cys (R463C), accounting for 42.2, 19.5 and 3.8 percent of the 498 mutant GBA1 alleles, respectively. Genotype frequencies reflected this distribution: 33 patients had a homozygous N370S genotype of whom a majority but not all stated that they were Jewish (all had non-neuronopathic type 1 disease); 20 were L444P homozygotes (all with neuronopathic disease); two patients were homozygous for $\mathrm{R} 463 \mathrm{C}$. Of the most frequent compound heterozygotes, 38 were N370S/L444P and 12 were L444P/R463C. Three of the seven patients with Parkinson disease were homozygous for N370S; of the other four, one was homozygous for R463C, two were $\mathrm{N} 370 \mathrm{~S} / \mathrm{L} 444 \mathrm{P}$ and one had the L444P/R463C compound GBA1 genotype. In patients originally classified as having type 1 disease, four fifths harboured at least one copy of N370S; in those classified as type 3 disease, nearly $90 \%$ had at least one copy of the recurrent L444P allele. Both alleles were present among the 40 patients who were neurologically re-evaluated; apart from those related to Parkinson disease, no patient habouring the N370S allele was found to have neurological signs. In the cohort as a whole, recombinant, splice-site, the $\operatorname{Rec} \Delta 5$ (del55bp) and novel mutant alleles, as well as previously described double missense mutations in cis (e.g. D409H + H255Q) were each identified in several patients (Additional file 1: Table S7).

\section{Skeletal manifestations}

The skeletal manifestations of Gaucher disease in this study cohort were clinically and radiologically diverse (Fig. 1, Table 2 and Additional file 2: Fig. S1). Quantification of the periodicity and presence or absence of bone pain entered into the Zimran Severity Score Index [36] was carried out at enrolment in 201 patients. Of these, 131 suffered pain (chronic in 31 patients, frequent in 34 , occasional in 41 , periodicity not stated in 25 ); pain occurred at all ages and only 70 were pain-free. The severity of skeletal pain, assessed by using the Gaucher Disease Type 1 Severity Scoring System, GD-DS3 [37], was recorded in a subset of patients $(n=129)$, and was extreme in two, severe in 14 , moderate in 47 , mild in 41 , and was not scored in 25 patients.

Symptomatic osteonecrosis, the most clinically significant and disabling skeletal manifestation of Gaucher disease, occurred in seventy-six patients. Among these, 43 had one episode and 33 had two or more episodes. Osteonecrosis caused bone pain in 45 or classical acute bone crisis in 30 cases, while only one patient had skeletal symptoms that were not painful. The median age at first episode of osteonecrosis in these 76 patients was 22 (range 4-64) years: of these, nearly 90\% occurred in the femur (distal or proximal), $4 \%$ occurred in the humeral head, $3 \%$ in the tibia and $4 \%$ at other sites.

Skeletal involvement in Gaucher disease includes reduced bone mineral density (BMD) which can be detected using dual-energy X-ray absorptiometry (DXA) and predisposes to fracture. Although most patients had had multiple DXA measurements between presentation and recruitment to the study, DXA determinations \pm 24 months from enrolment were available in a majority $(n=189$ spine; $n=165$ hip; $n=77$ forearm; Table 2). Overall median vertebral bone mineral density of L1-L4 was 0.982 (range $0.547-1.446$ ) $\mathrm{g} / \mathrm{cm}^{2}$. The median total hip and femoral neck BMD were 0.924 $(0.600-1.276)$ and $0.801(0.464-1.360) \mathrm{g} / \mathrm{cm}^{2}$, respectively. Median forearm density was $0.653(0.458-0.871)$ $\mathrm{g} / \mathrm{cm}^{2}$. Among postmenopausal women and men aged 50 years and older, 24 had DXA T-scores within the healthy reference range, while 34 had T-scores between -1 and -2.5 that are considered osteopaenic and $23 \mathrm{had}$ a T-score of -2.5 or lower-taken to indicate osteoporosis. Among premenopausal women and men younger than 50 years, 94 had DXA Z-scores within the expected range for age, while 17 had a Z-score of -2.0 or lower and thus below the expected range for age.

Sixteen males and 21 females had a history of one or more fragility fractures at any site; the median age at first fragility fracture was 36 (range 4-78) years. The spleen had been removed in twenty-three of the 37 . Of the total of 79 fragility fractures at recruitment, $30 \%$ had occurred in the spine; $29 \%$ in the hip/femur; $16 \%$ were in the ribs; $6 \%$ in the wrist and $19 \%$ occurred elsewhere. As detailed in Table 1, patients with type 3 disease generally had lower bone density at a younger age: those who suffered at least one fragility fracture, had their first episode earlier (median age 20 years, range: 4-50) than those with type 1 disease with one or more fragility fractures (median age 44 years, range: 13-78 years).

Radiological signs of osteoarthritis and frank osteolytic lesions were reported in 105 and 13 patients, respectively. Erlenmeyer flask deformity based on individual radiographic assessment was present in 80 out of the 125 adult patients for whom radiographs of the knee and distal femur were available for re-analysis. A defining ratio between the diameter of the femoral shaft $4 \mathrm{~cm}$ from the physis to the diameter of the physeal baseline of greater than 0.57 was used [38].

Orthopaedic surgery had been undertaken in sixtytwo patients: procedures were mainly carried out for joint destruction related to osteonecrosis but surgery was also required for fractures. 
Table 2 Bone manifestations and radiological characteristics of the GAUCHERITE cohort and subgroups at recruitment

\begin{tabular}{|c|c|c|c|c|c|c|}
\hline Variables & Categories* & $\begin{array}{l}\text { Entire cohort } \\
(\mathrm{N}=250)[\%]\end{array}$ & $\begin{array}{l}\text { Children } \\
(\mathrm{N}=26)[\%]\end{array}$ & $\begin{array}{l}\text { Adults } \\
(\mathrm{N}=224)[\%]\end{array}$ & $\begin{array}{l}\text { Gaucher Type } 1 \\
(\mathrm{~N}=223)[\%]\end{array}$ & $\begin{array}{l}\text { Gaucher Type } 3 \\
(\mathrm{~N}=27)[\%]\end{array}$ \\
\hline \multirow{6}{*}{$\begin{array}{l}\text { History of Fragility } \\
\text { fracture }\end{array}$} & Yes & 37 [15] & - & 37 [17] & 29 [13] & $8[30]$ \\
\hline & 1 fracture & 22 & - & 22 & 17 & 5 \\
\hline & $>1$ fracture & 15 & - & 15 & 12 & 3 \\
\hline & $\begin{array}{l}\text { Age at 1st event, } \\
\text { years, mean } \pm S D\end{array}$ & $38 \pm 19$ & - & $38 \pm 19$ & $42 \pm 18$ & $23 \pm 16$ \\
\hline & Median (range) & $36(4-78)$ & - & $36(4-78)$ & $44(13-78)$ & $20(4-50)$ \\
\hline & No & $213[85]$ & $26[100]$ & $187[83]$ & $194[87]$ & $19[70]$ \\
\hline \multirow[t]{5}{*}{ Fracture site } & Spine & 24 & - & 24 & 20 & 4 \\
\hline & Hip/Femur & 23 & - & 23 & 15 & 8 \\
\hline & Ribs & 12 & - & 12 & 10 & 2 \\
\hline & Wrist & 5 & - & 5 & 4 & 1 \\
\hline & Other bones & 15 & - & 15 & 14 & 1 \\
\hline \multirow{7}{*}{$\begin{array}{l}\text { History of Sympto- } \\
\text { matic Osteonecrosis }\end{array}$} & Yes & $76[30]$ & - & 76 [34] & $70[31]$ & $6[22]$ \\
\hline & 1 event & 43 & - & 43 & 39 & 4 \\
\hline & $\geq 2$ events & 33 & - & 33 & 31 & 2 \\
\hline & $\begin{array}{l}\text { Mean age } \pm S D \text { at } \\
\text { 1st event, years }\end{array}$ & $26 \pm 16$ & - & $26 \pm 16$ & $26 \pm 16$ & $14 \pm 2$ \\
\hline & Median age (range) & $22(4-64)$ & - & $22(4-64)$ & $22(4-64)$ & $14(12-16)$ \\
\hline & Age unknown & 4 & - & 4 & 2 & 1 \\
\hline & No & $174[70]$ & $26[100]$ & $148[66]$ & $153[69]$ & $21[78]$ \\
\hline \multirow{4}{*}{$\begin{array}{l}\text { Symptoms of } \\
\text { Osteonecrosis event }\end{array}$} & Yes & $76[30]$ & - & 76 [34] & $70[31]$ & $6[22]$ \\
\hline & $\begin{array}{l}\text { Classical acute bone } \\
\text { crisis }\end{array}$ & 30 & - & 30 & 27 & 3 \\
\hline & Pain & 45 & - & 45 & 42 & 3 \\
\hline & $\begin{array}{l}\text { Symptomatic, other } \\
\text { than pain }\end{array}$ & 1 & - & 1 & 1 & - \\
\hline \multirow{7}{*}{$\begin{array}{l}\text { Presence of bone/ } \\
\text { joint pain }\end{array}$} & Yes & $13152]$ & $4[15]$ & $127[57]$ & $118[53]$ & $13[48]$ \\
\hline & Continuous/chronic & 31 & - & 31 & 27 & 4 \\
\hline & Frequently & 34 & 1 & 33 & 31 & 3 \\
\hline & Occasional & 41 & 3 & 38 & 37 & 4 \\
\hline & $\begin{array}{l}\text { Pain periodicity not } \\
\text { recorded }\end{array}$ & 25 & - & 25 & 23 & 2 \\
\hline & No & $70[28]$ & $13[50]$ & $57[25]$ & $61[27]$ & $9[33]$ \\
\hline & Unknown & $49[20]$ & $9[35]$ & $40[18]$ & $44[20]$ & $5[19]$ \\
\hline \multirow{7}{*}{$\begin{array}{l}\text { Severity of bone/ } \\
\text { joint pain (GD1-DS3 } \\
\text { score) }\end{array}$} & Yes & $129[52]$ & $4[15]$ & $125[56]$ & $116[52]$ & $13[48]$ \\
\hline & Extreme & 2 & - & 2 & 2 & - \\
\hline & Severe & 14 & - & 14 & 13 & 1 \\
\hline & Moderate & 47 & 1 & 46 & 41 & 6 \\
\hline & Mild & 41 & 1 & 40 & 39 & 2 \\
\hline & $\begin{array}{l}\text { Pain severity not } \\
\text { recorded }\end{array}$ & 25 & 2 & 23 & 21 & 4 \\
\hline & Unknown & $121[48]$ & $22[85]$ & $99[44]$ & $107[48]$ & $14[52]$ \\
\hline \multirow[t]{2}{*}{ Lytic lesions } & Yes & $13[5]$ & - & $13[6]$ & $11[5]$ & $2[7]$ \\
\hline & No & 237 [95] & 26 [100] & 211 [94] & 212 [95] & 25 [93] \\
\hline \multirow[t]{2}{*}{ Osteoarthritis } & Yes & $105[42]$ & - & 105 47] & $100[45]$ & $5[19]$ \\
\hline & No & $145[58]$ & 26 [100] & $119[53]$ & $12355]$ & $22[81]$ \\
\hline \multirow{2}{*}{$\begin{array}{l}\text { Orthopaedic pro- } \\
\text { cedure }\end{array}$} & Yes & $62[25]$ & - & $62[28]$ & 55 [25] & $7[26]$ \\
\hline & No & $188[75]$ & 26 [100] & 162 [72] & 168 [75] & 20 [74] \\
\hline
\end{tabular}


Table 2 (continued)

\begin{tabular}{|c|c|c|c|c|c|c|}
\hline Variables & Categories* & $\begin{array}{l}\text { Entire cohort } \\
(\mathrm{N}=250)[\%]\end{array}$ & $\begin{array}{l}\text { Children } \\
(\mathrm{N}=26)[\%]\end{array}$ & $\begin{array}{l}\text { Adults } \\
(\mathrm{N}=224)[\%]\end{array}$ & $\begin{array}{l}\text { Gaucher Type } 1 \\
(\mathrm{~N}=223)[\%]\end{array}$ & $\begin{array}{l}\text { Gaucher Type } 3 \\
(\mathrm{~N}=27)[\%]\end{array}$ \\
\hline \multicolumn{7}{|l|}{ DXA } \\
\hline \multirow[t]{3}{*}{ Spine } & Number available & 189 & 15 & 174 & 171 & 18 \\
\hline & $\begin{array}{l}\mathrm{BMD}, \mathrm{g} / \mathrm{cm}^{2} \\
\text { mean } \pm \mathrm{SD}\end{array}$ & $0.984 \pm 0.150$ & $0.836 \pm 0.189$ & $0.997 \pm 1.139$ & $0.989 \pm 0.144$ & $0.937 \pm 0.196$ \\
\hline & Median (range) & $0.982(0.547-1.446)$ & $0.759(0.547-1.151)$ & $0.986(0.695-1.446)$ & $0.982(0.603-1.446)$ & $0.989(0.547-1.248)$ \\
\hline \multirow[t]{3}{*}{ Total Hip } & Number & 165 & 3 & 162 & 152 & 13 \\
\hline & $\begin{array}{l}\mathrm{BMD}, \mathrm{g} / \mathrm{cm}^{2} \\
\text { mean } \pm \mathrm{SD}\end{array}$ & $0.930 \pm 0.153$ & $0.716 \pm 0.133$ & $0.935 \pm 0.151$ & $0.934 \pm 0.153$ & $0.892 \pm 0.159$ \\
\hline & Median (range) & $0.924(0.600-1.276)$ & $0.687(0.600-0.861)$ & $0.926(0.607-1.276)$ & $0.923(0.607-1.276)$ & $0.874(0.600-1.253)$ \\
\hline \multirow[t]{3}{*}{ Femoral Neck } & Number & 165 & 3 & 162 & 152 & 13 \\
\hline & $\begin{array}{l}\mathrm{BMD}, \mathrm{g} / \mathrm{cm}^{2} \\
\text { mean } \pm \mathrm{SD}\end{array}$ & $0.813 \pm 0.152$ & $0.615 \pm 0.120$ & $0.816 \pm 0.151$ & $0.814 \pm 0.153$ & $0.793 \pm 0.152$ \\
\hline & Median (range) & $0.801(0.464-1.360)$ & $0.640(0.485-0.719)$ & $0.804(0.464-1.360)$ & $0.804(0.464-1.360)$ & $0.789(0.485-1.061)$ \\
\hline \multirow[t]{3}{*}{ Forearm } & Number & 77 & - & 77 & 70 & 7 \\
\hline & $\begin{array}{l}\mathrm{BMD}, \mathrm{g} / \mathrm{cm}^{2} \\
\text { mean } \pm \mathrm{SD}\end{array}$ & $0.658 \pm 0.103$ & - & $0.658 \pm 0.103$ & $0.660 \pm 0.104$ & $0.644 \pm 0.090$ \\
\hline & Median (range) & $0.653(0.458-0.871)$ & - & $0.653(0.458-0.871)$ & $0.654(0.458-0.871)$ & $0.632(0.513-0.778)$ \\
\hline
\end{tabular}

$B M D$ bone mineral density, DXA Dual-energy X-ray absorptiometry, GD1-DS3 Gaucher disease type 1 severity scoring system, SD standard deviation

${ }^{*}$ Categorical variables are expressed as frequency [percent]. Continuous variables are expressed as mean \pm SD and median (range)

\section{Neuronopathic disease}

Of the 27 patients with a diagnosis of chronic neuronopathic disease (type 3 ) at enrolment, the median age was 23 years (range: 5-60); four were older than 40 years. Neuronopathic features had often been detected after Gaucher disease was diagnosed: the most common presenting feature was a horizontal saccadic eye movement defect, typical of the disorder. After Gaucher disease had been diagnosed, formal recognition of the neuronopathic manifestations occurred within one year in 17 of the 27 patients, but in the remaining 10, these manifestations remained undocumented for between 2 and 48 years. Hepatosplenomegaly was the most frequent presenting manifestation, often in association with neurological signs, or as an incidental finding during assessment for an unrelated childhood illness, typically a respiratory complaint. In four patients, splenomegaly without clinical enlargement of the liver led directly to the diagnosis. One patient with neuronopathic Gaucher disease was identified after the diagnosis had been made in a sibling. In all four patients for whom longitudinal growth data were available, height velocity improved after enzyme infusions started; catch-up growth was accompanied by salutary changes in peripheral blood counts, hepatosplenomegaly and plasma chitotriosidase activity.

Two patients with neuronopathic Gaucher disease had received a bone marrow transplant as a primary intervention at the ages of 18 months and 11 years; the other patients are treated by enzyme therapy. Enzyme therapy was started at various times - before the age of 1 year to 41 years of age; median 3 years.

Impaired horizontal saccadic eye movement was present in all patients entering the study with neuronopathic Gaucher disease; more than $70 \%$ also had defective vertical saccadic movements. Strabismus was present in 22 (>80\%) of the patients (reflecting abducens nerve palsy); increased muscle tone and tendon reflexes were noted in 18 and intention tremor in 14 patients. Myoclonus and epilepsy, including myoclonic seizures, occurred in five patients. Disease severity, as determined by the modified Severity Scoring Tool (mSST) $[39,40]$, ranged from 0.5 to 19.5 at recruitment (higher scores indicating more severe disease; maximum 36); the mean score was 6.3 \pm 5.4 .

Patients with neuronopathic Gaucher disease at recruitment had non-neurological comorbidities. The most frequent were kyphosis (and/or scoliosis) and infiltrative lung disease-some patients had recurrent respiratory symptoms in the absence of a formal diagnosis of pulmonary infiltration. Of note, no patients were homozygous for the p.Asp448His (D409H) mutation in GBA1 and, as expected, none had the associated calcific cardiac valve disease nor aorto-coronary involvement.

\section{Other neurological manifestations}

Beyond the 27 patients assigned to type 3 (neuronopathic) disease at baseline as above, during the prospective study period, additional patients with neurological signs were found (see Fig. 2). Forty patients previously 


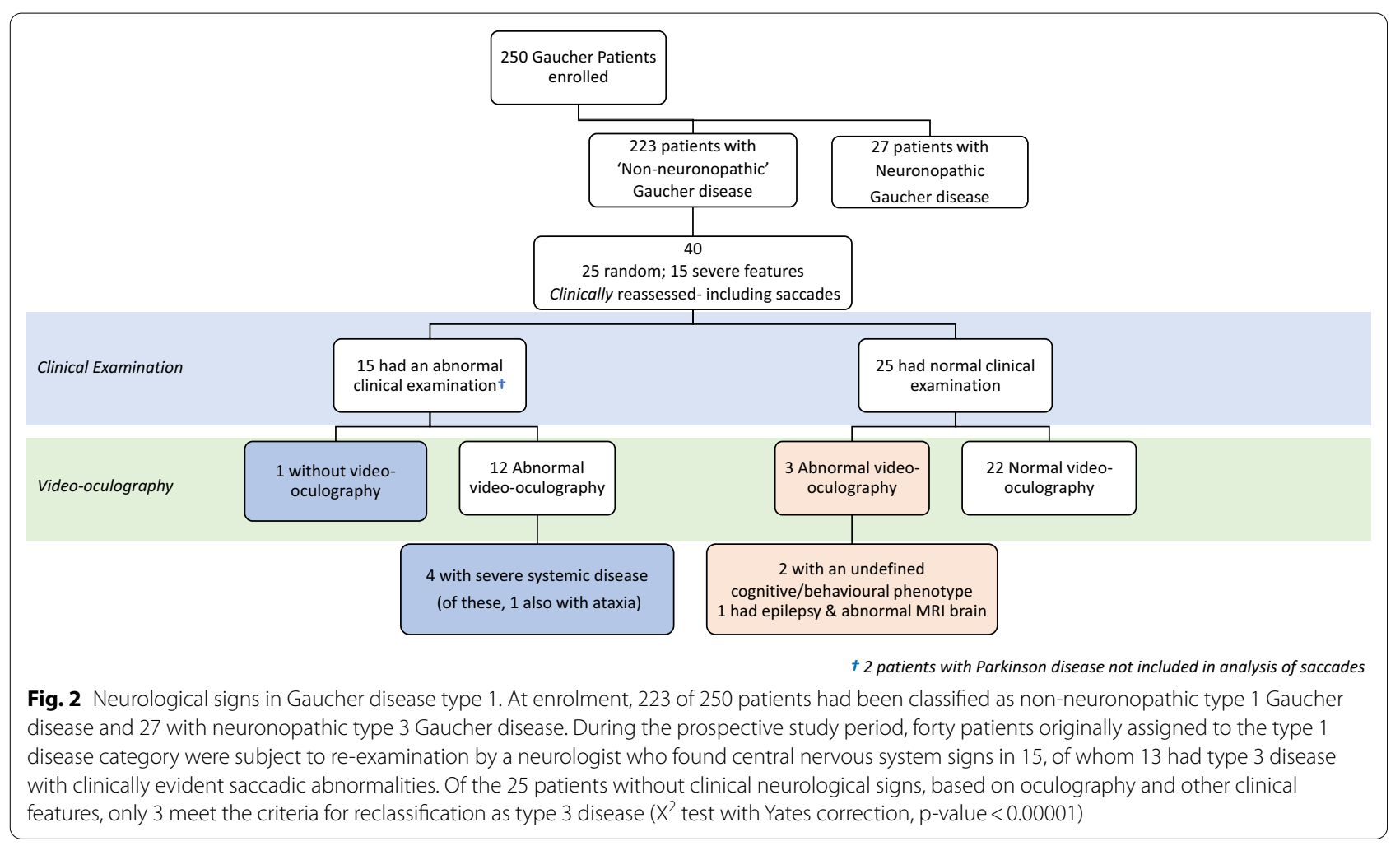

classified as type 1, non-neuronopathic Gaucher disease at enrolment, were examined opportunistically by a neurologist as a convenience sample. This supplementary examination included the assessment of saccadic eye movements as part of a parallel study and in all but one, a video-oculographic assessment was undertaken using EyeSeeCam [41]. Twenty-five patients were selected at random and 15 were examined because of clinical features of severe systemic disease and/or with GBA1 genotypes recognised to be adverse: L444P, R463C, W184R in homozygous or heterozygous form as well as rare alleles (including the RecNcil complex variant). Of note, several of these potentially adverse genotypes are also present in the remaining Gaucherite cohort not yet subject to independent re-examination by a neurologist.

As depicted in Fig. 2, of the forty patients in all, 25 had a normal clinical examination on review and of these, three had abnormal saccades detected by oculography and on careful scrutiny, other neurological features (two had an undefined cognitive and behavioural phenotype; the remaining patient suffered seizures with abnormal magnetic resonance brain imaging). Also as shown in the figure, fifteen of the forty re-examined patients had abnormal neurological signs-two had Parkinson disease. Development of Parkinson disease, with or without Lewy body dementia, is an uncommon but now recognised feature of type 1 Gaucher disease; abnormal oculography occurs in Parkinson disease [42]. The thirteen (non-Parkinsonian) patients with neurological signs, including abnormal ocular signs, may be eligible for reassignment to Gaucher disease type 3, since the presence of supranuclear ophthalmoplegia with abnormal saccades is claimed to be essential for the diagnosis of chronic neuronopathic Gaucher disease [43]. Four of these patients, were found to have florid manifestations of type 3 disease with additional severe systemic features that included kyphosis.

In summary, of the group of forty patients formerly classed as having type 1 disease who were later reviewed by a neurologist in this study, sixteen were found to have neurological signs associated with neuronopathic Gaucher disease and two had Parkinson disease. Individual $G B A 1$ genotypes in these patients, with totals in parenthesis, were: L444P/R463C (4); R463C/RecNci1 (4); L444P/P266R (1); L444P/P266A (1); R463C/ IVS2 + 1G (1); R463C/G377R (1); R463C/R257Q (1); R463C/R496C (1); RecNci1/ R262G (1); H311R/R359Q (1) (Additional file 1: Table S7).

\section{Other manifestations} Haematological findings

Within 30 days of enrolment, the mean haemoglobin was $139 \mathrm{~g} / \mathrm{L}$ (range 101-178) and the platelet count was $189 \times 10^{9} / \mathrm{L}$ (range: $39-489$ ). The effect of splenectomy 
on the platelet count was evident in the splenectomised subgroup compared with non-splenectomised patients; there was no material difference in haemoglobin concentration (Table 3).

\section{Pulmonary disease}

Pulmonary manifestations of Gaucher disease have been described but there is a lack of consensus about the nature of the pathological process and its classification. Eight patients with type 1 disease had pulmonary disease for which no other cause could be identified: thoracic imaging in this group, revealed bronchiectasis, fibrosis, interstitial disease (with nodules and interlobular septal thickening) and signs of pulmonary hypertension. Twenty-two patients with type 3 disease had intermittent respiratory symptoms: eight had recurrent respiratory infections or symptoms suggesting asthma; they had not undergone more detailed radiological investigation (e.g. computerized X-ray tomography). One patient had isolated pulmonary hypertension of unknown cause and the 13 remaining had bronchial and interlobular septal thickening, reticular-nodular shadowing with a groundglass appearance on tomographic scans; cystic changes also occurred. One patient had recurrent pneumothoraces: histology of pulmonary tissue and bronchoalveolar lavage from this patient showed Gaucher cell infiltration.
A further patient suffered pulmonary haemorrhages that required therapeutic embolisation. See Table 4.

\section{Hepatic disease}

Clinical features of liver disease with abnormal imaging with or without histopathological findings indicating fibrosis or cirrhosis not clearly attributable to fatty infiltration or alcoholic liver disease, were identified in fourteen patients ( 9 with type 1 , and 5 with type 3 Gaucher disease; Table 4). Eleven of these had been splenectomised and in several, the liver injury had been documented before enzyme therapy was started. In these 14 patients, the median interval between diagnosis of liver disease and Gaucher-specific therapy was 5.5 years but with a wide range-treatment having started 27 years before and up to 8 years after liver disease was recognized. Liver transplantation had been carried out in two patients: one had acute hepatic decompensation and the other, hepato-pulmonary syndrome. These individuals continue to receive enzyme therapy with good effect and were alive 19 and 21 years after transplantation. A further fourteen patients had structural liver abnormalities identified on imaging but a formal diagnosis by biopsy has not been made. The abnormalities include irregularity of the hepatic capsule, focal lesions, atrophy, calcification, and hepatic infarcts. More detailed studies on the hepatic and pulmonary manifestations of patients in the

Table 3 Laboratory characteristics of the GAUCHERITE cohort and subgroups at recruitment

\begin{tabular}{|c|c|c|c|c|c|c|}
\hline Variables & Categories* & Entire cohort $(\mathrm{N}=250)$ & $\begin{array}{l}\text { Children } \\
(N=26)\end{array}$ & $\begin{array}{l}\text { Adults } \\
(\mathrm{N}=224)\end{array}$ & Gaucher Type 1 ( $N=223)$ & Gaucher Type $3(\mathrm{~N}=27)$ \\
\hline \multirow[t]{3}{*}{ Haemoglobin } & Number & 211 & 11 & 200 & 193 & 18 \\
\hline & $\mathrm{g} / \mathrm{L}$, mean $\pm \mathrm{SD}$ & $139.5 \pm 13.9$ & $133.7 \pm 11.6$ & $139.9 \pm 14.0$ & $140.3 \pm 13.6$ & $131.3 \pm 15.2$ \\
\hline & Median (range) & $139(101-178)$ & $131(118-151)$ & $139(101-178)$ & $139(101-178)$ & $131(103-160)$ \\
\hline \multirow[t]{3}{*}{ With spleen } & Number & 157 & 11 & 146 & 146 & 11 \\
\hline & $\mathrm{g} / \mathrm{L}$, mean $\pm \mathrm{SD}$ & $140 \pm 15$ & $134 \pm 12$ & $141 \pm 15$ & $141 \pm 14$ & $129 \pm 17$ \\
\hline & Median (range) & $139(101-178)$ & $131(118-151)$ & $140(101-178)$ & $140(101-178)$ & $131(103-160)$ \\
\hline \multirow{3}{*}{ Without spleen } & Number & 54 & - & 54 & 47 & 7 \\
\hline & $\mathrm{g} / \mathrm{L}$, mean $\pm \mathrm{SD}$ & $137 \pm 11$ & - & $137 \pm 11$ & $138 \pm 11$ & $135 \pm 14$ \\
\hline & Median (range) & $138(116-163)$ & - & $138(116-163)$ & $138(116-163)$ & $131(120-153)$ \\
\hline \multirow[t]{3}{*}{ Platelet count } & Number & 208 & 11 & 197 & 190 & 18 \\
\hline & $10^{9} / \mathrm{L}$, mean $\pm S D$ & $200 \pm 74$ & $229 \pm 62$ & $198 \pm 74$ & $196 \pm 74$ & $244 \pm 52$ \\
\hline & Median (range) & 189 (39-489) & $213(151-337)$ & 187 (39-489) & 184 (39-489) & $234(147-337)$ \\
\hline \multirow[t]{3}{*}{ With spleen } & Number & 155 & 11 & 144 & 144 & 11 \\
\hline & $10^{9} / \mathrm{L}$, mean $\pm S D$ & $178 \pm 56$ & $229 \pm 62$ & $174 \pm 54$ & $173 \pm 53$ & $242 \pm 58$ \\
\hline & Median (range) & 175 (39-337) & $213(151-337)$ & $175(39-321)$ & $175(39-321)$ & $230(147-337)$ \\
\hline \multirow[t]{3}{*}{ Without spleen } & Number & 53 & - & 53 & 46 & 7 \\
\hline & $10^{9} / \mathrm{L}$, mean $\pm S D$ & $263 \pm 82$ & - & $263 \pm 82$ & $265 \pm 87$ & $248 \pm 46$ \\
\hline & Median (range) & $253(87-489)$ & - & $253(87-489)$ & $253.5(87-489)$ & $236(197-318)$ \\
\hline
\end{tabular}

$S D$ standard deviation

*Continuous variables are expressed as mean \pm SD and median (range). 
Table 4 Other manifestations of the GAUCHERITE cohort and subgroups at recruitment

\begin{tabular}{|c|c|c|c|c|c|c|}
\hline Variables & Categories* & $\begin{array}{l}\text { Entire cohort } \\
(\mathrm{N}=250)[\%]\end{array}$ & $\begin{array}{l}\text { Children } \\
(\mathrm{N}=26)[\%]\end{array}$ & $\begin{array}{l}\text { Adults } \\
(\mathrm{N}=224)[\%]\end{array}$ & $\begin{array}{l}\text { Gaucher Type } \\
1(\mathrm{~N}=223)[\%]\end{array}$ & $\begin{array}{l}\text { Gaucher Type } \\
3(\mathrm{~N}=27)[\%]\end{array}$ \\
\hline \multirow[t]{5}{*}{ Gallstones } & Yes & $79[32]$ & $1[4]$ & $78[35]$ & $7534]$ & $4[15]$ \\
\hline & Age at diagnosis, years, mean $\pm S D$ & $41 \pm 13$ & $16 \pm 0$ & $42 \pm 12$ & $42 \pm 12$ & $35 \pm 19$ \\
\hline & Median (range) & $40(11-66)$ & $16(16)$ & $40(11-66)$ & $40(11-66)$ & $35(16-55)$ \\
\hline & Age unknown & 5 & - & 5 & 5 & - \\
\hline & No & $171[68]$ & $25[96]$ & $146[65]$ & $148[66]$ & $23[85]$ \\
\hline \multirow[t]{3}{*}{ Path to diagnosis of gallstones } & Incidental & $43[54]$ & $1[100]$ & $42[54]$ & $40[53]$ & $375]$ \\
\hline & Symptoms prompted investigations & $32[41]$ & - & $32[41]$ & $31[41.5]$ & $1[25]$ \\
\hline & Unknown & $4[5]$ & - & $4[5]$ & $4[5.5]$ & - \\
\hline \multirow[t]{5}{*}{ Cholecystectomy } & Yes & $37[15]$ & $14]$ & $36[16]$ & $35[16]$ & $2[7]$ \\
\hline & $\begin{array}{l}\text { Age at cholecystectomy, years, } \\
\text { mean } \pm S D\end{array}$ & $39 \pm 13$ & $16 \pm 0$ & $39 \pm 12$ & $39 \pm 12$ & $35 \pm 28$ \\
\hline & Median (range) & $37(16-69)$ & 16 & $37(18-69)$ & $37(18-69)$ & $35(16-55)$ \\
\hline & Missing age & 1 & - & 1 & 1 & - \\
\hline & No & $213[85]$ & $25[96]$ & $188[84]$ & $188[84]$ & 25 [93] \\
\hline \multirow[t]{6}{*}{ Cancer } & Yes & $23[9]$ & - & $23[10]$ & $23[10]$ & - \\
\hline & Haematological & 4 & - & $4(17 \%)$ & $4(17 \%)$ & - \\
\hline & Non-haematological & 19 & - & $19(83 \%)$ & 19(83\%) & - \\
\hline & Age at diagnosis, years, mean \pm SD & $59 \pm 15$ & - & $58 \pm 15$ & $59 \pm 15$ & - \\
\hline & Median (range) & $62(18-83)$ & - & $62(18-83)$ & $62(18-83)$ & - \\
\hline & No & $227[91]$ & 26 [100] & $201[90]$ & $200[90]$ & $27[100]$ \\
\hline \multirow{4}{*}{$\begin{array}{l}\text { Hepatic } \\
\text { Disease }\end{array}$} & Yes & $14[6]$ & - & $14[6]$ & $9[4]$ & $5[19]$ \\
\hline & Age at diagnosis, years, mean $\pm S D$ & $40 \pm 17$ & - & $40 \pm 17$ & $47 \pm 12$ & $27 \pm 18$ \\
\hline & Median (range) & $41(6-75)$ & - & $41(6-75)$ & $45(37-75)$ & $24(6-55)$ \\
\hline & No & $236[94]$ & 26 [100] & $210[94]$ & 214 [96] & $22[81]$ \\
\hline \multirow[t]{4}{*}{ Pulmonary disease } & Yes & 29 12] & $831]$ & $21[9]$ & $7[3]$ & $22[81.5]$ \\
\hline & Age at diagnosis, years, mean $\pm S D$ & $19 \pm 22$ & $5 \pm 2$ & $24 \pm 24$ & $39 \pm 28$ & $12 \pm 15$ \\
\hline & Median (range) & $8(1-72)$ & $5(2-9)$ & $14(1-72)$ & $51(4-72)$ & $6(1-57)$ \\
\hline & No & $221[88]$ & $18[69]$ & 203 [91] & $216[97]$ & 5 [18.5] \\
\hline
\end{tabular}

SD standard deviation

*Continuous variables are expressed as mean \pm SD and median (range)

GAUCHERITE cohort will be reported separately and where possible this will include a systematic re-evaluation of the neurological findings across the entire cohort.

\section{Malignant disease}

Twenty-three patients with type 1 disease (of whom 9 were splenectomised) had documented cancer (median age 62 years, range: $18-83$ ). Of these, $>80 \%$ had nonhaematological cancer [ 7 cutaneous, 4 gastro-intestinal, 2 breast, 2 nervous system (cerebral meningioma and spinal cord tumour), one each of hepatic, renal, genitourinary tract and respiratory]. Of the four patients with haematological cancer, 3 had myeloma and one, B-cell lymphoma-Tables 4, 5 and 6 .

\section{Treatment status}

\section{Splenectomy}

Overall, one quarter of the patients had undergone splenectomy (median age of the procedure, 17 years,

Table 5 Splenectomy and non-haematological cancer

\begin{tabular}{lllll}
\hline Group & $\begin{array}{l}\text { Non- } \\
\text { haematological } \\
\text { cancer }\end{array}$ & Total size & Proportion* $^{*}$ P-value $^{\dagger}$ \\
\hline With spleen & 10 & 188 & 0.053 & 0.03 \\
Without spleen & 9 & 62 & 0.145 & \\
Total & 19 & 250 & & \\
\hline
\end{tabular}

*Proportion $=$ Non-haematological cancer/Total size

${ }^{\dagger}$ Fisher's Exact test P-value 
Table 6 Splenectomy and haematological cancer

\begin{tabular}{llrll}
\hline Group & $\begin{array}{l}\text { Haematological } \\
\text { cancer }\end{array}$ & Total size & Proportion* $^{*}$ & P-value $^{\dagger}$ \\
\hline With spleen & 4 & 188 & 0.021 & 0.58 \\
Without spleen & 0 & 62 & 0 & \\
Total & 4 & 250 & & \\
\hline
\end{tabular}

*Proportion $=$ Haematological cancer/Total size

${ }^{\dagger}$ Fisher's Exact test P-value

range: $1-58)$. The spleen has been removed in one third of those classified with type 3 Gaucher disease-in all instances in infancy and childhood (median age 5 years, range: 1-15). Three quarters of the splenectomies had been carried out before 1992-3, when tissue-derived enzyme therapy first became available in the European region before full regulatory approval: alglucerase was marketed from 1994 in Europe; the recombinant product, imiglucerase, was approved for marketing in 1997, followed by velaglucerase alfa in 2010 [20,44].

It is noteworthy that of the 15 patients who underwent splenectomy after 1993, cytopenia was an unusual indication. In eight patients, the spleen had been removed for diagnostic purposes (e.g. suspected malignancy) before referral to the specialist service; in a further three, the indication post-traumatic splenic rupture. Splenectomy was carried out for other reasons in three patients: inadequate responses to enzyme therapy with concern about bleeding risk, management of splenic infarction-and for an unknown indication in one patient.

\section{Haematopoietic stem-cell transplantation}

Two patients ( 1 man aged 46 and 1 woman, aged 30 years at recruitment) in the study had undergone haematopoietic stem cell transplantation as a primary intervention for Gaucher disease. Both share the p.Leu483Pro (L444P) homozygous genotype and have a classical "Norrbottnian" type 3 phenotype [6, 8, 45]. Transplantation from HLA-matched related donors was carried out in childhood (aged 11 years and 18 months, respectively). Splenectomy was undertaken before the procedure: growth and haematological parameters responded favourably-although kyphosis and neurological signs have slowly progressed in these patients. These surviving patients are among six transplanted in UK as originally pioneered by Hobbs and colleagues [46, 47].

\section{Enzyme and substrate-reduction therapies}

Two hundred and forty-three patients were receiving specific treatment for Gaucher disease within 6 months of recruitment to the study: velaglucerase alfa was given to 141 patients, imiglucerase to 89 , miglustat to 4 and eliglustat to 7 (Additional file 1: Table S6). At the time of writing, 65 patients are taking eliglustat and will be the subject of follow-up studies related to safety, tolerability and efficacy based on this cohort. Three patients were taking enzyme therapy combined with substratereduction therapy: velaglucerase alfa and miglustat in a patient with type 1 disease, and imiglucerase with eliglustat in two patients with type 3 Gaucher disease.

\section{Treatment-related adverse events}

Sixty-eight treatment-related adverse events (of which 36 were in patients receiving miglustat) had been reported in 43 patients. None of the reactions was life-threatening. As a result of adverse events, 25 users of miglustat had stopped this treatment. Seven patients receiving enzyme therapy stopped temporarily (1-4 months) and one permanently, switching to oral therapy (miglustat for 25 months and then eliglustat after a further 53 months). The six other patients all returned to enzyme therapy, one initially returned to alglucerase (in 1993) and two patients receiving taliglucerase alfa returned to either imiglucerase or velaglucerase. These latter are the only preparations currently approved in the UK. In the cohort, infusion reactions have been recorded in two patients: one developed migraine and having developed sensitivity to all three recombinant enzyme preparations, the other switched to oral therapy (eliglustat) after study lock.

\section{Bone specific therapies}

Seventy-five patients had received anti-resorptive and/ or anabolic drugs before recruitment. Within 6 months of enrollment, 94 patients in all had received a medication to treat or prevent skeletal disease (i.e. supplemental calcium and/or vitamin D, anti-resorptive or anabolic drugs). Seventy-nine patients had received calcium alone or in combination with vitamin D; 14 had received bisphosphonates alone or in combination with calcium and/or vitamin D supplements and one patient had received anabolic treatment in combination with calcium and vitamin D supplements (Additional file 1: Table S6).

\section{Effect of splenectomy on skeletal manifestations}

The occurrence of symptomatic osteonecrosis was strongly associated with splenectomy (Fig. 3A): controlling for gender, the hazard/intensity ratios for first and subsequent events were about 3 times greater in patients after splenectomy $(\mathrm{p}<0.0001)$. 


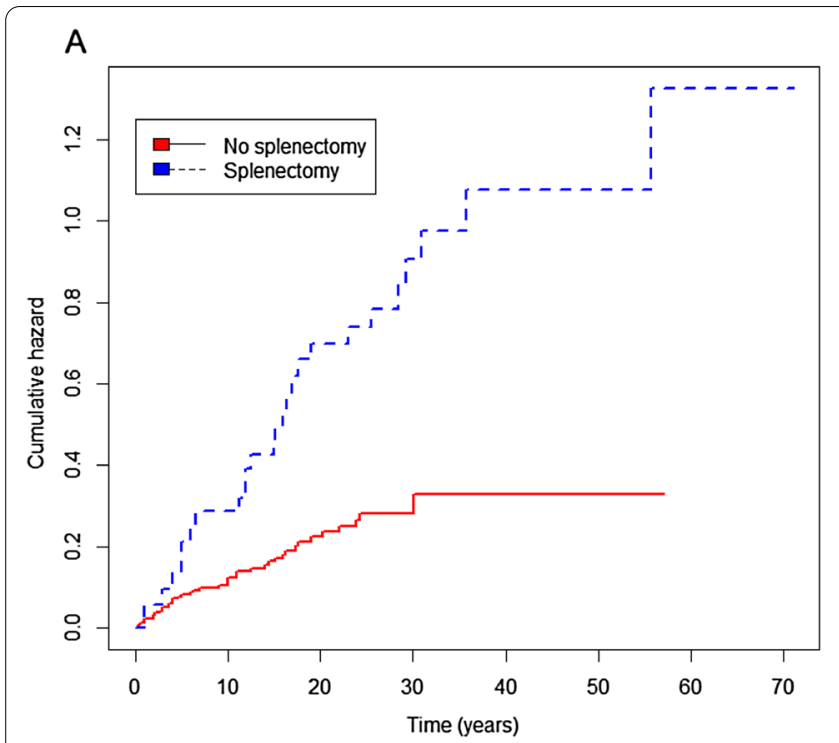

B

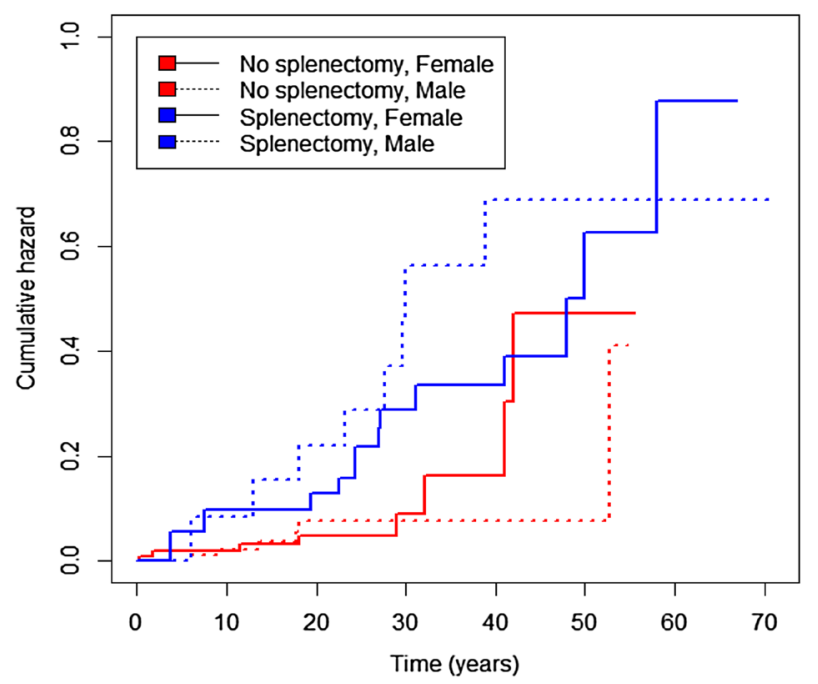

Fig. 3 Cumulative hazard for first osteonecrosis event and fragility fracture. Controlling for gender, the hazard or risk of having a first osteonecrosis event $(\mathbf{A})$ and first fragility fracture (B) after presentation of Gaucher disease was greater in patients who had splenectomy (hazard ratio of 3.32 [95\% $\mathrm{Cl} 1.74-5.00 ; \mathrm{p}<0.001]$ and 2.83 [95\% Cl 1.33-5.99; $\mathrm{p}=0.01$, respectively). Horizontal axis shows years after presentation with Gaucher disease

Splenectomy also influenced fracture risk (Fig. 3B). Controlling for gender, the hazard ratio for first fragility fracture in patients after undergoing splenectomy was nearly three-fold greater than those in whom the spleen was, or is intact $(p=0.01)$. Splenectomy was additionally associated with an approximately sixfold greater risk of repeated fragility fractures $(\mathrm{p}<0.0001)$. Figure 3 shows the temporal relationship to first skeletal events and the association of splenectomy, from diagnosis onwards: the two panels compare events for osteonecrosis and fragility fracture-depicting the interaction of age and gender in fragility fractures, in which a component risk due to the menopause in women would be predicted. Risk of osteolytic lesions and the occurrence of orthopaedic procedures were about 2.7- and twofold respectively higher after splenectomy, when controlled for gender $(\mathrm{p}=0.12$ and $\mathrm{p}=0.01$, respectively).

\section{Symptomatic osteonecrosis and fracture in relation to Gaucher-specific therapy}

Data from two hundred and forty-six patients were available for analysis of the relationship between the skeletal events and introduction of molecular therapies for Gaucher disease. Fifty-one first episodes of symptomatic osteonecrosis were documented in 242 patients when they were not receiving Gaucher-specific therapy (2136 person-years of follow-up), whereas 13 first events occurred in 180 patients after treatment, which was initially enzyme therapy (2493 person-years of follow$\mathrm{up}$ ), hazard ratio $0.2, \mathrm{p}<0.001$. At the time of data lock, too few patients have been exposed to the other specific interventions (marrow transplantation or substrate reduction therapy) for such analysis (Fig. 4). Age at which treatment began had no detectable effect.

In an Andersen-Gill analysis of 120 repeated events, the rate of symptomatic osteonecrosis was also reduced after specific treatment was started (hazard ratio 0.45 , $\mathrm{p}<0.001$ ) and again there was no age effect. In contrast, neither the time to first fragility fracture nor hazard of repeated fragility fractures was associated with any, or all of the combined specific treatments, nor was there an effect of age at which treatment started.

\section{Skeletal complications persist in patients receiving bone-specific treatment}

Males with Gaucher disease who had treatment given to improve bone density, on average had a lower fragility fracture rate $(\mathrm{p}<0.05)$ and incidence of lytic lesions $(\mathrm{p}<0.01)$ compared with females receiving bone modifying treatment. When followed over 15 years, the average fracture rate for males was 14.8 (95\% confidence interval 6.8 to 32.6$)$ per 100 person-years; the corresponding rate for females was 63.5 (43.5 to 92.7).

\section{Discussion}

In the group of more than eighty inborn lysosomal disorders, Gaucher disease is unique in its susceptibility to treatments and with sustained investment, the transformative efficacy of molecular therapies sets this ultrarare disorder alongside haemophilia and cystic fibrosis in 


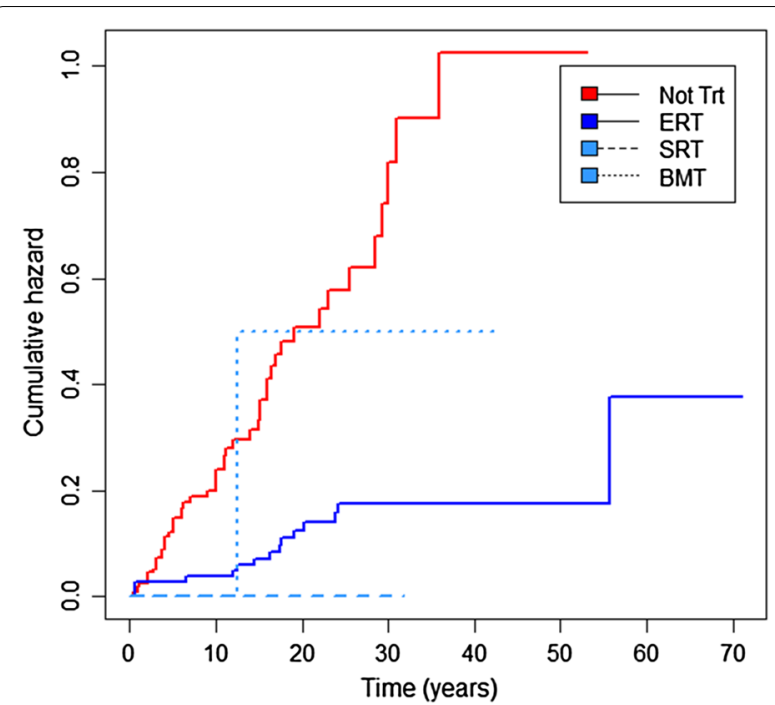

Fig. 4 Cumulative hazard for first osteonecrosis event according to treatment status. The hazard or risk of having a first osteonecrosis event after presentation of Gaucher disease was significantly lower after starting enzyme replacement therapy (ERT) than before (hazard ratio of $0.20 ; 95 \% \mathrm{Cl} 0.11-0.38 ; \mathrm{p}<0.001)$. The effects of substrate reduction therapy (SRT) and bone marrow transplantation (BMT) was difficult to assess owing to the low sample size (nine and two patients received SRT or BMT as first treatment, respectively). Of the two patients with BMT, one had their first episode of osteonecrosis after the procedure. Horizontal axis shows time in years after presentation of Gaucher disease

the Pantheon of orphan diseases. Biotechnological innovation has generated a diverse selection of drugs with distinct modes of action and indications. The competitive success of these ventures and marketing exclusivity of high-cost orphan drugs, mandate the need for independent therapeutic research that includes real-world data.

As in other advanced economies, most patients with Gaucher disease in the United Kingdom have received specific treatment but in the adults reported here, access to molecular therapies was often deferred until long after diagnosis. As a consequence, irreversible injury, especially to the skeleton and larger joints, became an inevitable burden. To appraise new treatments for this heterogeneous and chronic condition, powerful systems to collate, hold and comprehensively analyse extensive long-term data are needed.

GAUCHERITE is a platform concept with a national cohort of patients that seeks (1) to determine clinical burden; (2) characterize the clinical manifestations by in-depth phenotyping and (3) ultimately optimize management by therapeutic stratification of Gaucher disease. We focused principally on the skeletal aspects but also indicate the potential importance of timely recognition of neuronopathic features, which are associated with adverse progression of the bone disease. While no effective therapy for the neurological manifestations is as yet available, molecular therapies have salutary systemic effects which include manifestations in bone: nonetheless, persistent bone pain and disabling skeletal complications remain dominant unmet needs in many patients [48].

Our study is aligned to current stratification methodology [30]: use of longitudinal data of sufficient depth enables the effects of orphan drugs to be analysed even in a rare disease. Our approach has been validated, since patients were readily stratified in respect of two broad interventions: (1) splenectomy, a palliative measure to reduce the risk of bleeding and infection due to pancytopenia, and (2) introduction of molecular therapies.

In the era before specific therapies became available, splenectomy was required to ameliorate severe hypersplenism with the risk of life-threatening haemorrhage: however the procedure is strongly associated with recurrent osteonecrosis and, as shown here, also fragility fractures. Post-splenectomy fractures occur with markedly different trajectories according to gender-attributable to additional effects of osteoporosis at the menopause. The procedure signals a clinically distinct subgroup of patients with Gaucher disease with a high demand for orthopaedic services. As to cause and effect, we note that a forerunner of this study conducted in the UK population, identified a temporal relationship of osteonecrosis to the immediate years after splenectomy, indicating a causal relationship [49-54].

Mechanistic explanations for the diverse consequences of splenectomy include: (1) after the procedure, a greater burden of glycosphingolipids derived from the destruction of blood cells will fall on liver macrophages (Küpffer cells) and bone marrow. Greater encroachment by pathological macrophages will also induce greater local pro-inflammatory cytokine and chemokine release. We suggest that this will have adverse effects on the capillary network at junctional zones related to the growth plate and enhance the pathological accumulation of $\beta$-glucosylceramide a key ligand, of the mincle protein in macrophages and related osteoclasts [14, 15]. Poor perfusion will increase the risk of local ischaemia to the bone marrow; (2) splenectomy has multiple effects on the formed elements of the blood and increased viscosity and platelet aggregation index induces a thrombotic tendency [55]. Increased platelet numbers consequent upon the abrupt decrease in splenic pooling may also increase the risk of osteonecrosis; splenectomy is likely to amplify the changes in red-cell deformability due to alterations in the lipid composition of red-cell membranes [56]. Finally, increased red-cell rigidity will potentiate the effect of removing the spleen on the marrow compartment, since 
by analogy with sickle-cell disease, it will impair the deformability and flow properties of red cells within the microcirculation at watershed regions of oxygen and nutrient supply in long bones [57].

The greatly increased hazard of fragility fractures showed an incident pattern over time that differs between men and women: neither phenomenon has been reported. Although splenectomy in Gaucher disease is known to be associated with low bone mineral density [58], in this respect it resembles the effect of hyposplenism in sickle-cell anaemia, in which bone mineral density is greatly reduced [59]. Here we show a strong association with fragility fractures (Table 7 and Fig. 3). Of the 62 patients lacking a spleen, 21 had sustained multiple fragility fractures and 38 had developed osteonecrosis; these data compare with 16 and 38 of 188 Gaucher patients who had intact spleens, respectively. We argue that the link with the three-fold increased hazard of fragility fractures identified here is clinically important. Since completion of our analysis, investigation of an international registry of type 1 Gaucher patients has recently reported a multivariate analysis of fractures in three age cohorts among patients with known splenectomy status and at least one skeletal assessment on treatment (3216 of 6422 patients) [60]. Of note, a greater proportion of those splenectomized before enzyme treatment (with alglucerase or imiglucerase), had fractures (56\% greater risk of fracture post-splenectomy). The authors state that for patients aged 50 years or older when the therapy was first given, the analysis may have been affected by the exclusion of those who had suffered fractures during the long interval between the date of splenectomy and starting enzyme. Nonetheless in their report, the fracture risk attributed to the procedure was found only statistically significant $(\mathrm{p}=0.039)$ in adults aged between 18 and 50 years at the time enzyme treatment started.

The cause is not obvious and may either be a direct or indirect consequence of the procedure. We propose that rapidly progressive inflammatory disease with indications for early splenectomy-especially in young patients not promptly diagnosed and thus not optimally treated-may be the explanation. Florid Gaucher disease activity in childhood is a chronic inflammatory state that stunts growth and delays puberty-not only is modelling impaired with manifest osseous disease as above, but the achievable peak mass of bone is also decreased.

Splenectomy has potential consequences for the skeleton beyond osteonecrosis, risk of fracture and, possibly a trend towards more frequent osteolytic lesions. Since the risk of requiring orthopaedic surgery is also much greater in patients whose spleen has been removed $(p=0.01)$, the susceptibility to microbial infection and osteomyelitis (which preferentially affects injured bone-see Additional file 2: Fig. S1B) is likely to be greater. Overall, the findings reinforce the need for vigilant long-term monitoring of bone health in patients with Gaucher disease who have undergone splenectomy.

Splenectomy has other strong associations with clinical behaviour in this condition: there was a marked association with liver disease [61], with or without pulmonary disease, as has been previously reported [62]. Indeed, most of the patients with chronic liver disease, including manifest cirrhosis, who had interstitial lung disease or pulmonary hypertension, had had their spleen removed.

Table 7 Impact of splenectomy on skeletal manifestations since presentation of Gaucher disease

\begin{tabular}{|c|c|c|c|c|c|}
\hline & & Hazard ratio & P-value & {$[95 \% \mathrm{Cl}]$} & \\
\hline 1st fragility fracture & Splenectomy & 2.83 & 0.01 & 1.33 & 5.99 \\
\hline$N=247$ & Gender effect & 1.04 & 0.91 & 0.52 & 2.07 \\
\hline Multiple fragility fractures* & Splenectomy & 5.78 & $<0.0001$ & 2.32 & 14.42 \\
\hline$N=247$ & Gender effect & 0.59 & 0.17 & 0.28 & 1.24 \\
\hline 1st osteonecrosis & Splenectomy & 2.95 & $<0.0001$ & 1.74 & 5.00 \\
\hline$N=246$ & Gender & 0.80 & 0.37 & 0.48 & 1.31 \\
\hline Osteonecrosis events* & Splenectomy & 3.32 & $<0.0001$ & 1.98 & 5.56 \\
\hline$N=246$ & Gender effect & 0.95 & 0.83 & 0.59 & 1.53 \\
\hline Presence of Erlenmeyer flask deformity & Splenectomy & 0.98 & 0.95 & 0.59 & 1.64 \\
\hline$N=248$ & Gender effect & 0.80 & 0.34 & 0.50 & 1.27 \\
\hline Presence of lytic lesions & Splenectomy & 2.70 & 0.12 & 0.76 & 9.52 \\
\hline$N=248$ & Gender effect & 0.26 & 0.08 & 0.06 & 1.16 \\
\hline Orthopaedic surgery & Splenectomy & 1.99 & 0.01 & 1.15 & 3.44 \\
\hline$N=244$ & Gender effect & 0.84 & 0.52 & 0.50 & 1.41 \\
\hline
\end{tabular}

Origin: Gaucher disease presentation

*Event rate was estimated using Andersen-Gill method. 
An unexpected finding was the greater frequency of nonhaematological malignancies in patients after removal of the spleen: nine of 62, compared with 10 of 188 in the spleen-intact group $(\mathrm{p}<0.03)$, Table 5 . These differences are not explained by age distribution but confirm in our population, findings reported in other relatively small patient groups [63-66]. The possible effect of splenectomy on the development of various cancers in Gaucher disease has been recently reviewed [65] but the mechanism remains unclear [67]. We contend that these findings merit further exploration, particularly given the role of pathological sphingolipids in cell death, immune recognition and proliferation. That all four patients with haematological cancers were among the non-splenectomised group in our cohort, is a tantalizing matter of record.

Two hundred and forty-three patients were receiving a specific molecular therapy for Gaucher disease at the time of recruitment; in most cases enzyme therapy (velaglucerase alfa or imiglucerase) was used, but eleven patients were treated with substrate reduction therapy (eliglustat or miglustat). Three had combined therapies (eliglustat and imiglucerase; miglustat and velaglucerase alfa). At the time of writing, 65 patients, more than one quarter of the adult patients with type 1 Gaucher disease, are treated with the orally active, systemic substratereducing agent, eliglustat.

Specific treatment for Gaucher disease can reverse bone marrow infiltration, cytopenia and visceromegaly and ameliorate symptoms with improved quality of life. However, persistent skeletal pain is a notorious feature and an important cause of disability [48, 49, 68-70]. In this cohort, despite the emergence of molecular therapies, bone pain was present in more than half of the patients at enrolment, indicating that many UK patients had skeletal disease established before the interventions became generally available [49, 52]. Many also-especially women-had persistent fragility fractures, osteonecrosis and lytic lesions requiring orthopaedic surgery. Nonetheless, it is clear that the introduction of specific treatments exerted a protective effect on the disabling and painful consequences of osteonecrosis. In this study, disease-modifying therapy for Gaucher disease had no effect on fracture rate: this might be explained by the arrested and thus premature attainment of peak bone mass which cannot be further enhanced. As a result, the risk of fracture would be more resistant to modification. We specifically explored the effect of the age at which treatment started on either osteonecrosis or fracture, in the era of specific therapy but no association was found in this cohort. This might have resulted from the interaction of two opposing effects: once diagnosed in children and young adults, when the disease tends to be severe, early treatment is available to arrest its progress; while in older adults the condition can be severe, the later the age at which treatment is instituted may also imply intrinsically milder disease. In general, however, the interval between diagnosis and starting specific treatment for Gaucher disease is confirmed to be an important determinant of therapeutic outcome in the skeleton $[49,52]$. The unequivocal preventative effects of enzymatic augmentation and other interventions on osteonecrosis events, make it clear that the course of this disease can now be favourably modified.

Formerly, the diagnosis of patients with type 1 disease was mainly in adult life and often long after the onset of symptoms; those designated as type 3 Gaucher disease were nearly all identified in childhood. While this distinction reflects the often aggressive presentation of Gaucher type 3 disease, with greater awareness and improved services in the molecular era, the trend has not continued. Ostensibly non-neuronopathic disease is increasingly recognised in children and, as we show, more subtle neuronopathic forms of the disease may develop in adults. Careful follow-up of Gaucher patients in Japan who were homozygous for the L444P GBA1 allele but with non-neuronopathic disease in childhood, demonstrated the onset and evolution of neuronopathic features over time [71]. In the European and North-American literature $[68-70,72]$, as here, most patients are considered to have 'non-neuronopathic' rather than neuronopathic disease, despite the additional long-term risk of developing Parkinson disease and/or Lewy body dementia with accompanying neuropathology [18].

We uncovered more patients with features compatible with neuronopathic disease than expected in the UK population; these patients appear to be at a greater risk of developing early skeletal as well as other systemic manifestations of Gaucher disease [13, 73, 74]. Twenty-seven of the 250 were noted originally to have neuronopathic disease but a further 16 had features indicative of type 3 disease based principally on proven ophthalmic signs, suggesting an evolving pattern in some patients. The findings point to greater phenotypic variation than generally reported in the literature and further question the wisdom of assigning a subtype and phenotypic classification to a patient with Gaucher disease without neurological review-especially within the early years of diagnosis. With this in mind and prompted by the initial findings in a limited sample group, we plan systematically to re-evaluate the neurological features of the entire cohort. The need for intensified clinical monitoring mandated by the high risk of skeletal and other systemic manifestations in patients with neuronopathic disease will allow timely disease-modifying therapy to be introduced [33, 43]. It is now clear that diverse neurological features are found in 
all categories of Gaucher disease and represent a burden of illness globally which has not been fully appreciated in the Western and anglophone literature $[2,8]$.

The nature of this cohort, in which most patients were receiving specific treatment at the time of enrolment, required use of an analytical method that enables therapeutic stratification based on repeated evaluation of the outcomes and complications of the disease over time $[44,60]$. Despite the great rarity of Gaucher disease, many clinical publications have depended on data in registries supported by the biopharmaceutical industry, which naturally place emphasis on particular products and help to meet the requirements imposed by regulatory agencies. We reasoned that an established but more independent National cohort would be needed to stratify clinical outcomes and disease behaviour in a period of intense commercial therapeutic development and would foster further research. We suggest that the study differs importantly from the international commercial registries and contend that the GAUCHERITE cohort has advantages which, in toto, also differentiate it from the pioneering and instructive non-commercial initiatives of investigators in individual countries such as the Netherlands, Spain and France [69, 70, 72, 73]: (1) the study represents a long-established national disease population in patients attending specialist centres at state-funded University hospitals which, unlike private healthcare, are obliged to follow agreed clinical guidelines and uniform practices; (2) all approved treatments and clinical services are funded by the UK National Health Service; (3) clinical investigators are unbiased with respect to the manufacturer of molecular therapies - all disease-related drugs and nutritional supplements and their doses are captured; (4) the study and clinical research programme is subject to a single overarching national ethical review and approval process; (5) high-level data completion across the cohort without incentives such as third-party remuneration to investigators; (6) the study requires detailed completion of structured protocols for clinical history and physical findings with serial patient-reported outcomes, including formal QOL questionnaires; (7) a single database, with mass storage of $>2500$ variables, holds all radiological images of radiology and DXA scanning including linked narrative reports downloaded from the study centres; (8) use of the data is governed by an independently approved Data Management policy, allowing investigators access to anonymised data and curated serial Biobanked blood and tissue samples linked to the relational GAUCHERITE database; (9) the research and publication policy is governed by an independent management oversight committee chaired by a senior patient advocate and charity founder.
Scrutiny of this large dataset emphasises the value of systematic phenotyping by investigators with long-term specialist engagement in the care of patients affected by an ultra-rare disease. The strength of the cohort is that it spans the pre-treatment era and subsequent interventions. The extent and depth of data is founded on repeated year-on-year serial tests (median 26) and utilises comprehensive records in a relational database that allow linear analysis using the repeated mixed measures model of individual timed events. The transformative effects of the therapies combined with intense phenotyping, time-to-event analysis and historical depth in diverse domains of the disease are also advantages.

\section{Conclusions}

The GAUCHERITE cohort, which comprises $85 \%$ of all patients known to have Gaucher disease in the United Kingdom, represents an independent, data-rich platform to study the epidemiology and course of this heterogeneous disorder. We show that the database is a source of information that allows clinical effectiveness and appropriateness of care to be investigated in real-world clinical practice; the data can moreover be explored in depth by stratifying patients according to potentially divergent treatment effects. Finally, the cohort is an opportune resource by which to appraise newly introduced and future therapies.

\section{Abbreviations}

BMD: Bone mineral density; DXA: Dual-energy X-ray absorptiometry; ERT: Enzyme replacement therapy; GAUCHERITE: Gaucher Investigative Therapy Evaluation; GD-DS3: Gaucher Disease Type 1 Severity Scoring System; NHS: National Health Service; SD: Standard deviation; SRT: Substrate reduction therapy; UK: United Kingdom.

\section{Supplementary Information}

The online version contains supplementary material available at https://doi. org/10.1186/s13023-021-02034-6.

Additional file 1. Deep Phenotyping of Gaucher disease with supplementary materials, methods, results and references.

Additional file 2: Fig. 1. Magnetic resonance imaging of skeletal manifestations in Gaucher disease.

\section{Acknowledgements}

The exceptional commitment of patients with Gaucher disease, the UK Gauchers Association, Mr. Jeremy Manuel OBE, Ms. Tanya Collin-Histed and Ms. Sarah Allard, was critical for successful recruitment of the cohort; they engaged enthusiastically with the study from its conception. We are grateful also to Drs. Alex Broomfield, James Davison, Elaine Murphy and Uma Ramaswami, for their help with the clinical study, to Iguazu Ltd for helping to develop and implement the GAUCHERITE database and Fjola Johannesdottir for image retrieval. Senior representatives from the biopharmaceutical partners: Actelion (now Johnson and Johnson), SHIRE (now part of Takeda) \& Sanofi (formerly Genzyme) for pro bono advice and expertise on logistics and support for team-building. EQ-5D-5L ( EuroQol Research Foundation. EQ-5D ${ }^{\mathrm{TM}}$ is a trademark of the EuroQol Research Foundation, mSST NGD, NART, FAB, ACE_R were 
provided free of charge. We thank Dr Lucy Collins for help with UPDRS and the Core Biochemical Assay Laboratory (Mr. Keith Burling and Mr. Peter Barker) at Cambridge University hospitals for CCL-18/PARC assays. GBA1 genotyping was done by sequencing genomic DNA at University of Manchester Centre for Integrated Genomic Medical Research (Drs. Heather Church and Glenda Beaman under supervision of Professor William G. Newman, supported by Dr. Siddharth Banka); Dr Kerri Wallom in the Oxford Laboratory collated and stored study samples for further biomarker development. We thank Sister Elizabeth Morris of the Lysosomal Disorders Unit at Addenbrooke's hospital and other specialist nurses and support staff for their sustained advice and assistance. Picture Archiving and Communication System (PACS) team members kindly facilitated image downloading. Sooyoung Lee diligently extracted, transcribed and handled the clinical and laboratory data. GAUCHERITE: Chief Investigator, TM Cox, University of Cambridge; co-Principal Investigator, FM Platt, Department of Pharmacology, University of Oxford; Principal clinical investigators (listed in alphabetical order followed by the specialist centre): S Banka, Manchester Centre for Genomic Medicine, St Mary's Hospital, Manchester; A Chakrapani, Great Ormond Street Hospital; P B Deegan, Cambridge University Hospital; T Geberhiwot, Birmingham Queen Elizabeth Hospital; DA Hughes, Royal Free Hospital University College London; S Jones, Manchester University NHS Foundation Trust, Manchester; RH Lachmann, National Hospital for Neurology and Neurosurgery, Queen's Square London; S Santra, Birmingham Women's and Children's Hospital, R Sharma, Hope hospital Salford, Manchester; A Vellodi, Great Ormond Street London.

\section{Authors' contributions}

All authors contributed materially to the work of this project: conceptualization of the research questions, study design and/or interpretation of the results. All reviewed the manuscript. SD, KP and AD contributed equally to the conduct of the research and KP first drafted the manuscript; KT and BT conducted the statistical analyses. All authors approved the final manuscript.

\section{Funding}

The UK Medical Research Council funded this study (2013-9) under the Stratified Medicine Programme scheme, (GAUCHERITE, MR/K015338/1); the research was co-funded by the National Institute for Health Research (NIHR) Cambridge Biomedical Research Centre (Grant Number IS-BRC-1215-20014) that in part supported SD, AD and KP. An add-on contribution to independent statistical support (KT) was kindly donated by Shire International GmbH (2018 9). The views expressed are those of the authors and not necessarily those of the NHS, the NIHR or the Department of Health and Social Care.

\section{Availability of data and materials}

The data that support the findings of this study are held by the University of Cambridge under an MRC approved Data Management Policy. Restrictions apply and data are not publicly available: applications from bona fide organizations will be considered by the University of Cambridge and clinical governance of Cambridge University NHS Foundation Trust Hospitals and also subject to approval by the Gaucherite Consortium Management Committee.

\section{Declarations}

\section{Ethical approval and consent to participate}

This study was conducted according to the principles of the Declaration of Helsinki (2013) [75]. Ethical approval was given by the national ethics review committee (14/EE/1168) under the purview of the NHS Research and Development (R\&D) in the United Kingdom and from the local R\&D boards at each of the eight participating specialist clinical centres. Informed consent was obtained from all subjects at the time of enrolment into GAUCHERITE. The research cohort is registered with ClinicalTrials.gov, NCT code, 03240653.

\section{Consent to publish}

No restrictions.

\section{Competing interests}

SHIRE Biopharmaceuticals UK (now part of Takeda) supported the licence fee for the SF-36v2 questionnaire $(<\$ 6000)$. The authors confirm that neither SHIRE nor any other external agency played any part in the study design, data collection, analysis - nor interpretation. The named authors are solely responsible for the manuscript and the decision to submit it for publication.

\section{Author details}

${ }^{1}$ Department of Medicine, University of Cambridge, Cambridge, UK. ${ }^{2}$ Medical Research Council Biostatistics Unit, University of Cambridge, Cambridge, UK. ${ }^{3}$ Cambridge University Hospitals, Cambridge, UK. ${ }^{4}$ Manchester Centre for Genomic Medicine, St Mary's Hospital, Manchester University NHS Foundation Trust, University of Manchester, Manchester, UK. ${ }^{5}$ Royal Free Hospital, London, UK. ${ }^{6}$ Salford Royal NHS Foundation Trust, Salford, UK. ${ }^{7}$ National Hospital for Neurology and Neurosurgery, London, UK. ${ }^{8}$ Great Ormond Street Hospital, London, UK. ${ }^{9}$ Birmingham Queen Elizabeth Hospital, Birmingham, UK. ${ }^{10}$ Birmingham Children's Hospital, Birmingham, UK. ${ }^{11}$ Present Address: Manchester Centre for Genomic Medicine, St Mary's Hospital, Manchester, UK. ${ }^{12}$ Present Address: Centre for Trials Research, Cardiff University, Cardiff, UK.

Received: 22 May 2021 Accepted: 19 September 2021

Published online: 14 October 2021

\section{References}

1. Brady RO, Kanfer JN, Shapiro D. Metabolism of glucocerebrosides. Evidence of an enzymatic deficiency in Gaucher's disease. Biochem Biophys Res Commun. 1965;18:221-5.

2. Beutler E, Grabowski GA. The metabolic and molecular basis of inherited disease. 8th ed. New York: McGraw-Hill Book Co.; 2001.

3. Dahl N, Hillborg PO, Olofsson A. Gaucher disease (Norrbottnian type III): probable founders identified by genealogical and molecular studies. Hum Genet. 1993;92(5):513-5.

4. Chaves RG, Pereira LV, de Araujo FT, Rozenberg R, Carvalho MD, Coelho $J C$, et al. Consanguinity and founder effect for Gaucher disease mutation G377S in a population from Tabuleiro do Norte, Northeastern Brazil. Clin Genet. 2015;88(4):391-5.

5. Nalysnyk L, Rotella P, Simeone JC, Hamed A, Weinreb N. Gaucher disease epidemiology and natural history: a comprehensive review of the literature. Hematology. 2017;22(2):65-73.

6. Cox TM, Schofield JP. Gaucher's disease: clinical features and natural history. Baillières Clin Haematol. 1997;10(4):657-89.

7. Lachmann RH, Grant IR, Halsall D, Cox TM. Twin pairs showing discordance of phenotype in adult Gaucher's disease. QJM. 2004;97(4):199-204.

8. Grabowski GA. Phenotype, diagnosis, and treatment of Gaucher's disease. Lancet. 2008;372(9645):1263-71.

9. Biegstraaten M, van Schaik IN, Aerts JM, Langeveld M, Mannens MM, Bour $L$, et al. A monozygotic twin pair with highly discordant Gaucher phenotypes. Blood Cells Mol Dis. 2011;46(1):39-41.

10. Mistry PK, Cappellini MD, Lukina E, Ozsan H, Mach PS, Rosenbaum H, et al. A reappraisal of Gaucher disease-diagnosis and disease management algorithms. Am J Hematol. 2011;86(1):110-5.

11. Aerts JM, Hollak CE. Plasma and metabolic abnormalities in Gaucher's disease. Baillieres Clin Haematol. 1997;10(4):691-709.

12. CoxTM. Gaucher disease: understanding the molecular pathogenesis of sphingolipidoses. J Inherit Metab Dis. 2001;24(Suppl 2):106-21.

13. Stirnemann J, Belmatoug N, Camou F, Serratrice C, Froissart R, Caillaud C, et al. A review of Gaucher disease pathophysiology, clinical presentation and treatments. Int J Mol Sci. 2017;18(2):441.

14. Nagata M, Izumi Y, Ishikawa E, Kiyotake R, Doi R, Iwai S, et al. Intracellular metabolite beta-glucosylceramide is an endogenous Mincle ligand possessing immunostimulatory activity. Proc Natl Acad Sci USA. 2017;114(16):E3285-94.

15. Andreev D, Liu M, Weidner D, Kachler K, Faas M, Gruneboom A, et al. Osteocyte necrosis triggers osteoclast-mediated bone loss through macrophage-inducible C-type lectin. J Clin Invest. 2020;130(9):4811-30.

16. Conradi NG, Sourander P, Nilsson O, Svennerholm L, Erikson A. Neuropathology of the Norrbottnian type of Gaucher disease. Morphol Biochem Stud Acta Neuropathol. 1984;65(2):99-109.

17. Kaye EM, Ullman MD, Wilson ER, Barranger JA. Type 2 and type 3 Gaucher disease: a morphological and biochemical study. Ann Neurol. 1986;20(2):223-30.

18. Wong K, Sidransky E, Verma A, Mixon T, Sandberg GD, Wakefield LK, et al. Neuropathology provides clues to the pathophysiology of Gaucher disease. Mol Genet Metab. 2004;82(3):192-207.

19. Cox TM. Gaucher disease: clinical profile and therapeutic developments. Biologics. 2010;4:299-313. 
20. Deegan PB, Cox TM. Imiglucerase in the treatment of Gaucher disease: a history and perspective. Drug Des Dev Ther. 2012;6:81-106.

21. Rosenbloom BE, Weinreb NJ. Gaucher disease: a comprehensive review. Crit Rev Oncog. 2013;18(3):163-75.

22. Pastores GM, Hughes DA. Gaucher Disease. GeneReviews. 2000.

23. Cox T, Lachmann R, Hollak C, Aerts J, van Weely S, Hrebicek M, et al. Novel oral treatment of Gaucher's disease with N-butyldeoxynojirimycin (OGT 918) to decrease substrate biosynthesis. Lancet. 2000;355(9214):1481-5.

24. Shayman JA. Developing novel chemical entities for the treatment of lysosomal storage disorders: an academic perspective. Am J Physiol Renal Physiol. 2015;309(12):F996-9.

25. Mistry PK, Lukina E, Ben TH, Amato D, Baris H, Dasouki M, et al. Effect of oral eliglustat on splenomegaly in patients with Gaucher disease type 1: the ENGAGE randomized clinical trial. JAMA. 2015;313(7):695-706.

26. Mistry PK, Lukina E, Ben TH, Shankar SP, Baris H, Ghosn M, et al. Outcomes after 18 months of eliglustat therapy in treatment-naive adults with Gaucher disease type 1: The phase 3 ENGAGE trial. Am J Hematol. 2017:92(11):1170-6.

27. CoxTM, Drelichman G, Cravo R, Balwani M, Burrow TA, Martins AM, et al. Eliglustat maintains long-term clinical stability in patients with Gaucher disease type 1 stabilized on enzyme therapy. Blood. 2017;129(17):2375-83.

28. Lukina E, Watman N, Dragosky M, Lau H, Avila AE, Rosenbaum H, et al. Outcomes after 8 years of eliglustat therapy for Gaucher disease type 1: Final results from the Phase 2 trial. Am J Hematol. 2019;94(1):29-38.

29. Mistry PK, Balwani M, Charrow J, Kishnani P, Niederau C, Underhill LH, et al. Real-world effectiveness of eliglustat in treatment-naive and switch patients enrolled in the International Collaborative Gaucher Group Gaucher Registry. Am J Hematol. 2020;95(9):1038-46.

30. Robinson PN. Deep phenotyping for precision medicine. Hum Mutat. 2012:33(5):777-80.

31. Cozar M, Bembi B, Dominissini S, Zampieri S, Vilageliu L, Grinberg D, et al. Molecular characterization of a new deletion of the GBA1 gene due to an inter Alu recombination event. Mol Genet Metab. 2011;102(2):226-8.

32. den Dunnen JT. Sequence variant descriptions: HGVS nomenclature and mutalyzer. Curr Protoc Hum Genet. 2016;90:7.

33. Bremova-Ertl T, Schiffmann R, Patterson MC, Belmatoug N, Billette DV, Bardins S, et al. Oculomotor and vestibular findings in Gaucher disease type 3 and their correlation with neurological findings. Front Neurol. 2017;8:711.

34. Schneider E, Villgrattner T, Vockeroth J, Bartl K, Kohlbecher S, Bardins S, et al. EyeSeeCam: an eye movement-driven head camera for the examination of natural visual exploration. Ann N Y Acad Sci. 2009;1164:461-7.

35. Bonjour JP, Ammann P, Rizzoli R. Importance of preclinical studies in the development of drugs for treatment of osteoporosis: a review related to the 1998 WHO guidelines. Osteoporos Int. 1999;9(5):379-93.

36. Zimran A, Kay A, Gelbart T, Garver P, Thurston D, Saven A, et al. Gaucher disease. Clinical, laboratory, radiologic, and genetic features of 53 patients. Medicine. 1992;71(6):337-53.

37. Weinreb NJ, Cappellini MD, CoxTM, Giannini EH, Grabowski GA, Hwu WL, et al. A validated disease severity scoring system for adults with type 1 Gaucher disease. Genet Med. 2010;12(1):44-51.

38. Carter A, Rajan PS, Deegan P, Cox TM, Bearcroft P. Quantifying the Erlenmeyer flask deformity. Br J Radiol. 2012;85(1015):905-9.

39. Davies EH, Surtees R, DeVile C, Schoon I, Vellodi A. A severity scoring tool to assess the neurological features of neuronopathic Gaucher disease. J Inherit Metab Dis. 2007;30(5):768-82

40. Davies EH, Mengel E, Tylki-Szymanska A, Kleinotiene G, Reinke J, Vellodi A. Four-year follow-up of chronic neuronopathic Gaucher disease in Europeans using a modified severity scoring tool. J Inherit Metab Dis. 2011;34(5):1053-9.

41. Donald A, Tan CY, Chakrapani A, Hughes DA, Sharma R, Cole D, et al. Eye movement biomarkers allow for the definition of phenotypes in Gaucher Disease. Orphanet J Rare Dis. 2020;15(1):349.

42. MacAskill MR, Anderson TJ, Jones RD. Adaptive modification of saccade amplitude in Parkinson's disease. Brain. 2002;125(Pt 7):1570-82.

43. Schiffmann R, Sevigny J, Rolfs A, Davies EH, Goker-Alpan O, Abdelwahab $M$, et al. The definition of neuronopathic Gaucher disease. J Inherit Metab Dis. 2020;43(5):1056-9.

44. Barton NW, Brady RO, Dambrosia JM, Di Bisceglie AM, Doppelt SH, Hill SC, et al. Replacement therapy for inherited enzyme deficiency-macrophage-targeted glucocerebrosidase for Gaucher's disease. N Engl J Med. 1991;324(21):1464-70.

45. Desnick RJ. Gaucher disease: a century of delineation and understanding. Prog Clin Biol Res. 1982;95:1-30.

46. Hobbs JR, Jones KH, Shaw PJ, Lindsay I, Hancock M. Beneficial effect of pre-transplant splenectomy on displacement bone marrow transplantation for Gaucher's syndrome. Lancet. 1987;1 (8542):1111-5.

47. Starer F, Sargent JD, Hobbs JR. Regression of the radiological changes of Gaucher's disease following bone marrow transplantation. Br J Radiol. 1987;60(720):1189-95.

48. Hughes D, Mikosch P, Belmatoug N, Carubbi F, Cox T, Goker-Alpan O, et al. Gaucher disease in bone: from pathophysiology to practice. J Bone Miner Res. 2019;34(6):996-1013.

49. Deegan PB, Pavlova E, Tindall J, Stein PE, Bearcroft P, Mehta A, et al. Osseous manifestations of adult Gaucher disease in the era of enzyme replacement therapy. Medicine (Baltimore). 2011;90(1):52-60.

50. Pastores GM, Patel MJ, Firooznia H. Bone and joint complications related to Gaucher disease. Curr Rheumatol Rep. 2000;2(2):175-80.

51. Pastores GM, Weinreb NJ, Aerts H, Andria G, CoxTM, Giralt M, et al. Therapeutic goals in the treatment of Gaucher disease. Semin Hematol. 2004;41(4 Suppl 5):4-14.

52. Mistry PK, Deegan P, Vellodi A, Cole JA, Yeh M, Weinreb NJ. Timing of initiation of enzyme replacement therapy after diagnosis of type 1 Gaucher disease: effect on incidence of avascular necrosis. Br J Haematol. 2009;147(4):561-70.

53. Khan A, Hangartner T, Weinreb NJ, Taylor JS, Mistry PK. Risk factors for fractures and avascular osteonecrosis in type 1 Gaucher disease: a study from the International Collaborative Gaucher Group (ICGG) Gaucher Registry. J Bone Miner Res. 2012;27(8):1839-48.

54. Mistry PK, Weinreb NJ, Kaplan P, Cole JA, Gwosdow AR, Hangartner T. Osteopenia in Gaucher disease develops early in life: response to imiglucerase enzyme therapy in children, adolescents and adults. Blood Cells Mol Dis. 2011;46(1):66-72.

55. Bax BE, Richfield L, Bain MD, Mehta AB, Chalmers RA, Rampling MW. Haemorheology in Gaucher disease. Eur J Haematol. 2005;75(3):252-8.

56. Franco M, Collec E, Connes P, van den Akker E, Billette DV, Belmatoug $\mathrm{N}$, et al. Abnormal properties of red blood cells suggest a role in the pathophysiology of Gaucher disease. Blood. 2013;121(3):546-55.

57. Bunn HF. Pathogenesis and treatment of sickle cell disease. N Engl J Med. 1997:337(11):762-9.

58. Pastores GM, Wallenstein S, Desnick RJ, Luckey MM. Bone density in Type 1 Gaucher disease. J Bone Miner Res. 1996;11(11):1801-7.

59. Adesina OO, Gurney JG, Kang G, Villavicencio M, Hodges JR, Chemaitilly W, et al. Height-corrected low bone density associates with severe outcomes in sickle cell disease: SCCRIP cohort study results. Blood Adv. 2019:3(9):1476-88.

60. Deegan P, Khan A, Camelo JS Jr, Batista JL, Weinreb N. The International Collaborative Gaucher Group GRAF (Gaucher Risk Assessment for Fracture) score: a composite risk score for assessing adult fracture risk in imiglucerase-treated Gaucher disease type 1 patients. Orphanet J Rare Dis. 2021;16(1):92

61. Lachmann RH, Wight DG, Lomas DJ, Fisher NC, Schofield JP, Elias E, et al. Massive hepatic fibrosis in Gaucher's disease: clinico-pathological and radiological features. QJM. 2000;93(4):237-44.

62. Mistry PK, Sirrs S, Chan A, Pritzker MR, Duffy TP, Grace ME, et al. Pulmonary hypertension in type 1 Gaucher's disease: genetic and epigenetic determinants of phenotype and response to therapy. Mol Genet Metab. 2002;77(1-2):91-8.

63. Fleshner PR, Aufses AH Jr, Grabowski GA, Elias R. A 27-year experience with splenectomy for Gaucher's disease. Am J Surg. 1991;161(1):69-75.

64. Lo SM, Stein P, Mullaly S, Bar M, Jain D, Pastores GM, et al. Expanding spectrum of the association between Type 1 Gaucher disease and cancers: a series of patients with up to 3 sequential cancers of multiple types - correlation with genotype and phenotype. Am J Hematol. 2010;85(5):340-5

65. Mistry PK, Taddei T, vom Dahl S, Rosenbloom BE. Gaucher disease and malignancy: a model for cancer pathogenesis in an inborn error of metabolism. Crit Rev Oncog. 2013;18(3):235-46.

66. Zimran A, Liphshitz I, Barchana M, Abrahamov A, Elstein D. Incidence of malignancies among patients with type I Gaucher disease from a single referral clinic. Blood Cells Mol Dis. 2005;34(3):197-200. 
67. Dubot P, Astudillo L, Therville N, Sabourdy F, Stirnemann J, Levade T, et al. Are glucosylceramide-related sphingolipids involved in the increased risk for cancer in gaucher disease patients? Review and hypotheses. Cancers (Basel). 2020;12(2):475.

68. Charrow J, Andersson HC, Kaplan P, Kolodny EH, Mistry P, Pastores G, et al. The Gaucher registry: demographics and disease characteristics of 1698 patients with Gaucher disease. Arch Intern Med. 2000;160(18):2835-43.

69. Giraldo P, Alfonso P, Irun P, Gort L, Chabas A, Vilageliu L, et al. Mapping the genetic and clinical characteristics of Gaucher disease in the Iberian Peninsula. Orphanet J Rare Dis. 2012;7:17.

70. Stirnemann J, Vigan M, Hamroun D, Heraoui D, Rossi-Semerano L, Berger MG, et al. The French Gaucher's disease registry: clinical characteristics, complications and treatment of 562 patients. Orphanet J Rare Dis. 2012:7:77.

71. Ida H, Rennert OM, Iwasawa K, Kobayashi M, Eto Y. Clinical and genetic studies of Japanese homozygotes for the Gaucher disease L444P mutation. Hum Genet. 1999;105(1-2):120-6.

72. Zimran A, Belmatoug N, Bembi B, Deegan P, Elstein D, Fernandez-Sasso D, et al. Demographics and patient characteristics of 1209 patients with
Gaucher disease: descriptive analysis from the Gaucher Outcome Survey (GOS). Am J Hematol. 2018;93(2):205-12.

73. Biegstraaten M, van Schaik IN, Aerts JM, Hollak CE. 'Non-neuronopathic' Gaucher disease reconsidered. Prevalence of neurological manifestations in a Dutch cohort of type I Gaucher disease patients and a systematic review of the literature. J Inherit Metab Dis. 2008;31(3):337-49.

74. Detollenaere C, Benghergbia M, Brassier A, de Villemeur TB, Amsallem D, Berger M, et al. Type 3 Gaucher disease, diagnostic in adulthood. Mol Genet Metab Rep. 2017;13:1-2.

75. World Medical Association Declaration of Helsinki. ethical principles for medical research involving human subjects. JAMA. 2013;310(20):2191-4.

\section{Publisher's Note}

Springer Nature remains neutral with regard to jurisdictional claims in published maps and institutional affiliations.
Ready to submit your research? Choose BMC and benefit from:

- fast, convenient online submission

- thorough peer review by experienced researchers in your field

- rapid publication on acceptance

- support for research data, including large and complex data types

- gold Open Access which fosters wider collaboration and increased citations

- maximum visibility for your research: over $100 \mathrm{M}$ website views per year

At BMC, research is always in progress.

Learn more biomedcentral.com/submissions 